University of Arkansas, Fayetteville

ScholarWorks@UARK

Graduate Theses and Dissertations

$12-2019$

\title{
Surface Modification of PVDF Membranes for Treating Produced Waters by Direct Contact Membrane Distillation
}

Zahra Anari

University of Arkansas, Fayetteville

Follow this and additional works at: https://scholarworks.uark.edu/etd

Part of the Hydraulic Engineering Commons, and the Water Resource Management Commons

\section{Citation}

Anari, Z. (2019). Surface Modification of PVDF Membranes for Treating Produced Waters by Direct Contact Membrane Distillation. Graduate Theses and Dissertations Retrieved from https://scholarworks.uark.edu/etd/3430

This Thesis is brought to you for free and open access by ScholarWorks@UARK. It has been accepted for inclusion in Graduate Theses and Dissertations by an authorized administrator of ScholarWorks@UARK. For more information, please contact scholar@uark.edu. 
Surface Modification of PVDF Membranes for Treating Produced Waters by Direct Contact Membrane Distillation

A thesis submitted in partial fulfillment

of the requirements for the degree of

Master of Science in Chemical Engineering

by

\section{Zahra Anari}

Amirkabir University of Technology

Bachelor of Science in Chemical Engineering, 2013

University of Tehran

Master of Science in Chemical Engineering, 2015

December 2019

University of Arkansas

This thesis is approved for recommendation to the Graduate Council.

Ranil Wickramasinghe, Ph.D.

Thesis Director

David Ford, Ph.D.

Wen Zhang, Ph.D.

Committee Member

Committee Member 


\begin{abstract}
Direct contact membrane distillation is a promising unit operation for treating hydraulic fracturing flow back and produced water. However, while a hydrophobic membrane is essential to prevent the passage of water from the feed to the permeate side, fouling by dissolved organic species can compromise membrane performance and result in wetting of the membrane pores. Here four monomers, hydroxyethylmethacrylate, acrylic acid, 1-vinyl-3-allylimidazolium bromide, and 1-vinyl-3-hexylimidazolium bromide have been grafted from the surface of a PVDF membrane. The modified and base membranes were tested in a direct contact membrane distillation system. All membranes were challenged with real produced water. In addition, base membranes and membranes modified by grafting 1-vinyl-3-allylimidazolium bromide were challenged with produced water that was pretreated by electrocoagulation. These membranes were also challenged with a synthetic wastewater made by adding to DI water the major inorganic compounds present in the produced water. The highest fluxes were obtained for the membrane grafted with 1-vinyl-3-allylimidazolium bromide chains. The membrane surface after membrane distillation was analyzed by scanning electron microscopy and energy-dispersive X-ray (EDX) spectroscopy. For all membranes, the interaction between adsorbed organic and inorganic species determines the degree of fouling and hence the loss in flux and membrane stability. Polyionic liquid chains that contain a repeating charged species and hydrophobic segments minimized fouling by organic species and improved the flux and membrane stability. The results suggest that by carefully tuning the properties of the monomer units in the polymer chains, membrane stability and performance can be improved.
\end{abstract}




\section{Acknowledgments}

I appreciate my advisor Dr. Ranil Wickramasinghe, for all his contributions and funding to this research. I also would like to appreciate all the support and the encouragement I received from Dr. David Ford, the Department Head of Chemical Engineering program. I am very thankful to my committee member, Dr. Wen Zhang for her advice and help along the way.

I gratefully acknowled ge the funding source by Southwestern Energy through the National Science Foundation Industry/University Cooperative Research Center for Membrane Science, Engineering and Technology, the National Science Foundation (IIP 1361809) and the University of Arkansas.

Thank you.

Zahra Anari 


\section{Dedication}

To whom this may be enlightenment. 


\section{Table of Contents}

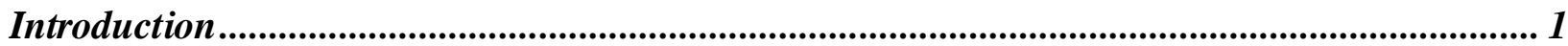

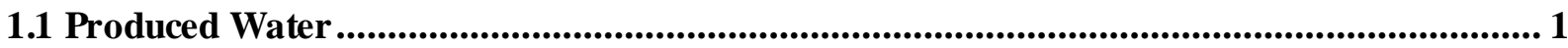

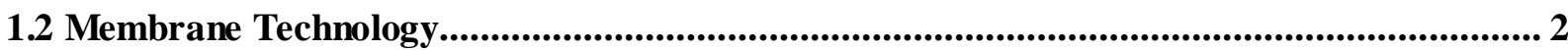

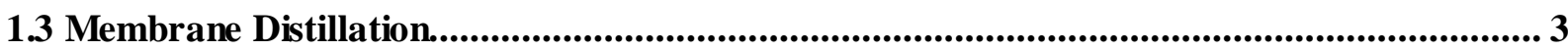

1.3.1 Foulin g Mitigation ........................................................................................................................

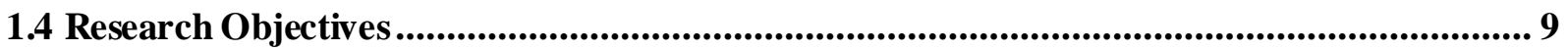

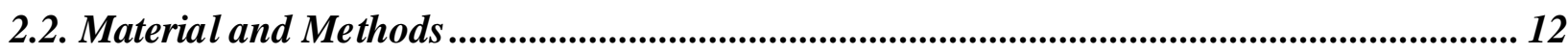

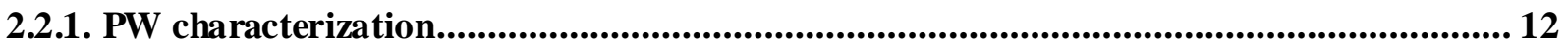

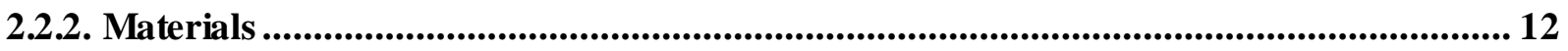

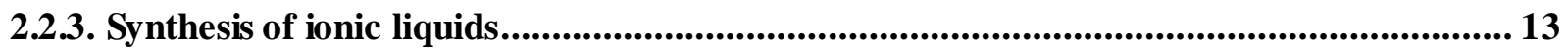

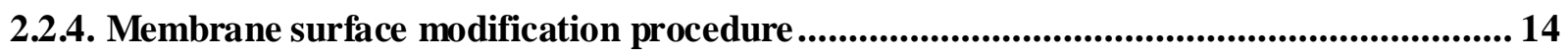

2.2.5. Characterization of modified membranes.................................................................. 17

2.2.5.1. Fourier-transform infra red (FTIR) spectroscopy …..........................................................................17

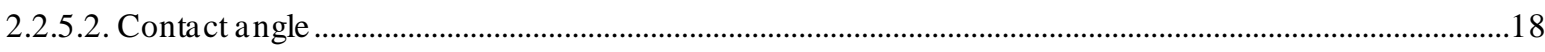

2.2.5.3. Scanning electron microscopy (SEM) and energy-dispersive X-ray (EDX) spectroscopy ...................18

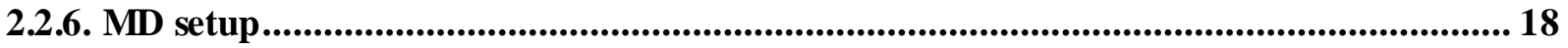

2.2.7. Electrocoagulation setup............................................................................................ 20

2.3. Results and discussion ................................................................................................... 21

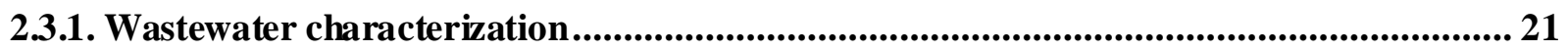

2.3.2 Modification of hydrophobic PVDF membrane.......................................................... 22

2.3.3. Surface characterization of the modified membrane ................................................. 23 


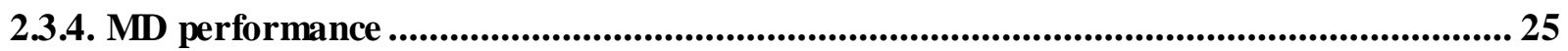

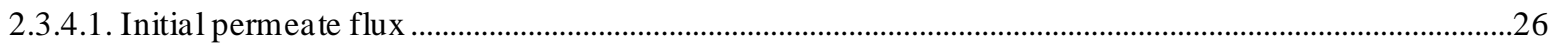

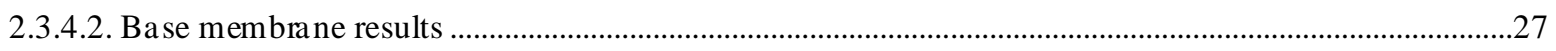

2.3.4.3. Modified membrane results ................................................................................................................

2.3.4.3.1. Ally 1 modified membrane ....................................................................................................................3

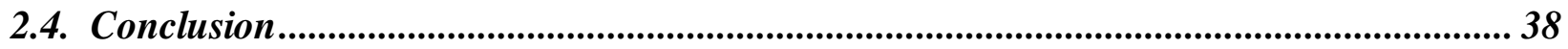

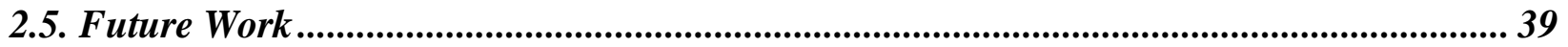

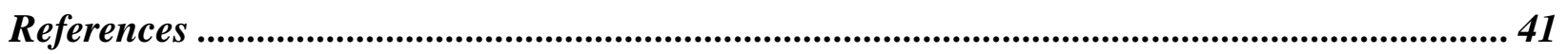




\section{List of Tables}

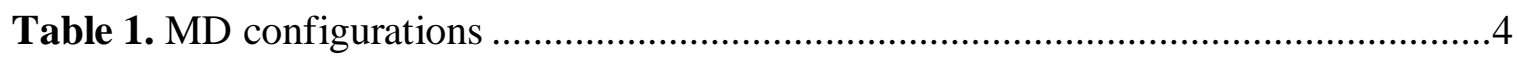

Table 2. Monomer structures and characteristics.................................................... 11

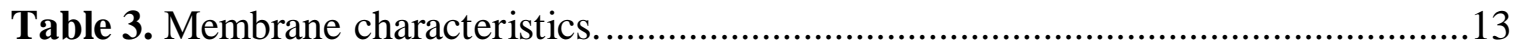

Table 4. Water quality analy sis for PW and PW after electrocoagulation ......................22

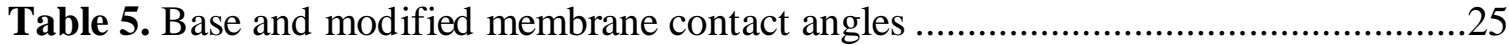




\section{List of Figures}

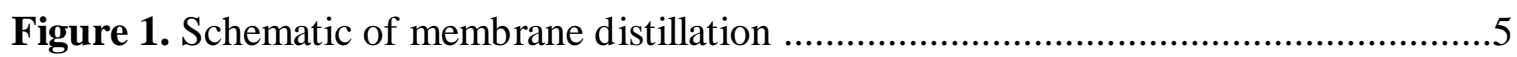

Figure 2. Schematic representation of reactions during EC pretreatment .........................8

Figure 3. Surface grafting modification procedure ........................................................17

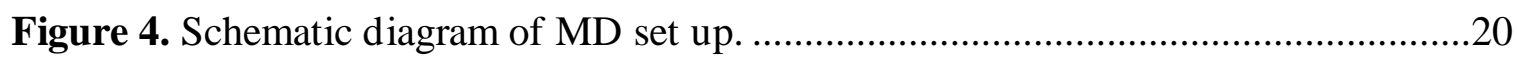

Figure 5. FTIR spectra of the base and modified PVDF membranes...............................24

Figure 6. Percentage removal of TDS, TSS, TOC and turbidity during electrocoagulation of PW. .26

Figure 7. Initial water flux for base and modified membranes. Membranes were challenged with PW except where noted. EC $=$ PW pretreated by electrocoagulation, Synthetic $=$ synthetic PW.27

Figure 8. Normalized water flux for base membrane challenged with PW, pretreated PW and synthetic $\mathrm{PW}$.

Figure 9. SEM images and EDX spectroscopy results for base membrane after MD with a and d) $\mathrm{PW}, \mathrm{b}$ and e) pretreated PW and $\mathrm{c}$ and $\mathrm{f}$ ) synthetic $\mathrm{PW}$.

Figure 10. Normalized water flux for a) HEMA, AA, and b) polyionic liquids modified membranes. The feed consisted of PW, results for the base membrane are also included (dashed line).

Figure 11. Water flux of modified membranes as a function of cumulative permeate volume over three MD cycles for a) HEMA and AA modified membranes b) ionic liquids modified membranes. The feed consisted of PW. MD was stopped and regeneration commenced when the flux dropped below $6.0 \mathrm{~L} \mathrm{~m}^{-2} \mathrm{~h}^{-1}$ 33

Figure 12. a) SEM image and b) EDX spectroscopy results of Allyl modified membrane after three MD cycles with PW, respectively. 34

Figure 13. a) Normalized water flux of Allyl modified PVDF membrane challenges with PW, pretreated PW and synthetic PW. EDX results for Allyl modified after MD with b) pretreated PW, c) synthetic PW. .36 


\section{List of Published Papers}

Z. Anari, A. Sengupta, K. Sardari, S.R. Wickramasinghe, Surface Modification of PVDF Membranes for Treating Produced Waters by Direct Contact Membrane Distillation, Separation and Purification Technology, 224 (2018) 388-396 ${ }^{1,2}$.

\footnotetext{
${ }^{1}$ My contribution to this work was conducting the experiments, analyzing the data and writing the initial manuscript.

2 This thesis includes some modifications in the Introduction, and Materialand Methods sections of the paper.
} 


\section{Introduction}

\subsection{Produced Water}

Petroleum and natural gas are major nonrenewable sources of energy and assets for many countries today. Oil and gas production has been described as one of the biggest industrial activities in the twenty-first century [1]. These products are trapped within shale formations, which are laminated sedimentary rocks consisting of fine particles. One common characteristic of these formations is very low permeability. Although they naturally have small fractures, they lack sufficient permeability for the recovery of oil and gas at rates suitable for large-scale production. Therefore, fractures must be engineered to enable efficient recovery. Hydraulic fracturing is the injection of additional water into the reservoir under high pressure to lengthen well fractures and enhance the recovery. The stress imposed by the pressure creates interconnected cracks that increase the permeability of the rocks and enable higher oil and gas recovery [2] After hydraulic fracturing is applied, and pressure is relieved, approximately $10-40 \%$ of the injected fluid returns to the surface through the well. This fluid is known as flowback water, which mainly resembles the injected fluid composition. The flowback water composition changes as a function of the time that it is in contact with the formations inside the well; The more contact, the higher minerals and organic constituents dissolved in water. As oil and gas production continues, aqueous and nonaqueous liquid is produced continuously at the surface in much lower volumes. This water is known as produced water (PW), which contains very high TDS concentrations and is a mixture of injected water, formation water, hydrocarbons, and treating chemicals [3].

The global estimated PW volume-to-product ratio is 3:1 [4]. The United States (U.S.) Energy Information Administration estimates that about 15.8 trillion cubic feet (Tcf) of dry natural 
gas was produced directly from shale and tight oil resources in the U.S. in 2016, an increase from 0.3 Tcf in 2000 [5,6]. Currently, oil and gas operators manage PW with the following methods [1]:

- Injecting back PW into production wells; Treatment is required to reduce fouling and bacterial growth.

- Deep well injection into geologic formations with no potential to allow migration of pollutants to potential potable water aquifers.

- Reusing in petroleum industry operations such as for drilling; minimal treatment is required.

- Treating for usage in other applications such as irrigation, wildlife consumption and habitat, industrial water, and even drinking water; significant treatment is required.

Currently, deep well injection is the primary method to manage PW. However, handling this large amount of water is expensive. The water must be transported to the deep well injection site, often by a pipeline on the same production site. However, in many areas, PW is stored in tanks and transported by trucks to a commercial disposal facility. Because transporting water from these wells is expensive, PW treatment can be used to manage the wastewater with less cost than hauling it away. In addition, it can be seen as an opportunity to provide a valuable source of water for beneficial use in many applications [7].

\subsection{Membrane Technology}

An emerging treatment technology for PW is membrane technology. In a broad term, membrane filtration includes the physical separation of the unwanted impurities from the bulk solutions through a semipermeable membrane. Depending on the transport principle of the membrane technology, concentration, pressure, or temperature gradient is required for the operation of this technology. Membrane separation is a promising solution due to its advantages 
such as cost effectiveness, no usage of chemical additives, modular installation, and operation at ambient temperature [8]. Different types of membrane-based processes such as microfiltration (MF), ultrafiltration (UF), nanofiltration (NF), membrane distillation (MD), and reverse osmosis (RO) have been investigated to treat PW. MF and UF have relatively large pore sizes and are not suitable for TDS removal. Although RO and NF are frequently used for desalination, they are effective for treatment of low TDS waters (NF: TDS <15,000 $\mathrm{mg} \mathrm{L}^{-1}$, RO: TDS <50,000 $\mathrm{mg} \mathrm{L}^{-1}$ ) $[9,10]$. RO and NF require high hydraulic pressure to recover waterfrom a very high TDS solution. In contrast, MD can provide water recovery from very high TDS waters with high rejection factors using vapour pressure difference of both sides at conditions near to ambient temperature. However, they are susceptible to fouling in which oil, particles, and other PW components form a layer on the membrane surface. This leads to low flux and increases operating costs. Reducing membrane fouling and improving membrane operation can provide a decrease in operating costs and an increase in the application of membrane technology for PW treatment [11].

\subsection{Membrane Distillation}

MD is a thermally-driven separation process, whereby only vapor molecules transfer through a microporous hydrophobic membrane $[12,13]$. This separation method is driven by the vapour pressure difference induced by the temperature difference between both sides of the membrane. Advantages of this process over other membrane separation techniques include:

- Low operating temperatures compared to distillation processes; the feed solution is not required to be heated up to the boiling point.

- The hydrostatic pressure provided in this method is lower than that used in pressure-driven membrane processes like RO. 
- Using vapor pressure difference as the driving force, MD achieves high rejection factors.

MD can provide nearly complete rejection of TDS, maintaining dissolved non-volatile species in the reject stream and producing a high quality permeate. MD has four different configurations in order to apply a low vapor pressure on the permeate side. Table 1 shows the difference between configurations. In direct contact membrane distillation (DCMD), permeate solution is in direct contact with the membrane surface, while in air gap membrane distillation (AGMD) an air gap layer separates a cold condensing surface from the membrane. A cold sweep gas induces the driving force in sweep gas membrane distillation (SGMD), and vacuum pressure is used on the permeate side in vacuum membrane distillation (VMD) [13].

Table 1. MD configurations

\begin{tabular}{|c|c|c|c|}
\hline Configuration & Diagram & Advantage & Disadvantage \\
\hline DCMD & Hot Feed & $\begin{array}{l}\text { - High water flux } \\
\text { - Simple design }\end{array}$ & $\begin{array}{l}\text { - Low energy efficiency } \\
\text { (High heat conduction } \\
\text { loss) }\end{array}$ \\
\hline AGMD & 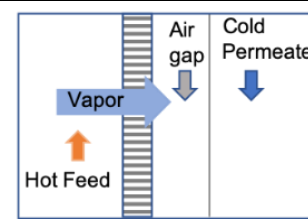 & - High energy efficiency & $\begin{array}{l}\text { - Low water flux (Air gap } \\
\text { limiting the mass } \\
\text { transfer) }\end{array}$ \\
\hline SGMD & 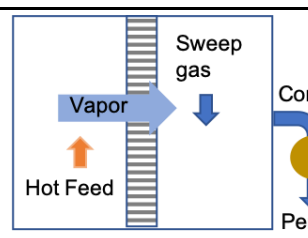 & $\begin{array}{l}\text { - Improved mass transfer } \\
\text { compared to AGMD }\end{array}$ & $\begin{array}{l}\text { - Sweep gas additional } \\
\text { cost } \\
\text { - External condenser }\end{array}$ \\
\hline VMD & 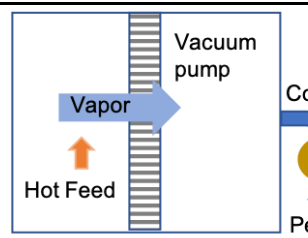 & $\begin{array}{l}\text { - Improved mass transfer } \\
\text { (removal of air in the } \\
\text { pores) }\end{array}$ & $\begin{array}{l}\text { - Electricity consumption } \\
\text { for vacuum pump }\end{array}$ \\
\hline
\end{tabular}


DCMD is the most studied arrangement of MD in the lab scale due to the simplicity in design, easy operation, and high fluxes [14-19]. The membrane acts as a thermal insulator as well as a physical barrier between the hot feed and the cold distillate that flow on the opposite side of the membrane. Water molecules evaporate at the feed-membrane surface, and vapour molecules are transferred to the permeate side by the imposed vapour pressure difference across the membrane and condense at the distillate side of the membrane module. Due to the hydrophobic characteristic of the membrane, only the gas phase penetrates the membrane pores [20]. Figure 1 shows the concept of DCMD for PW treatment.

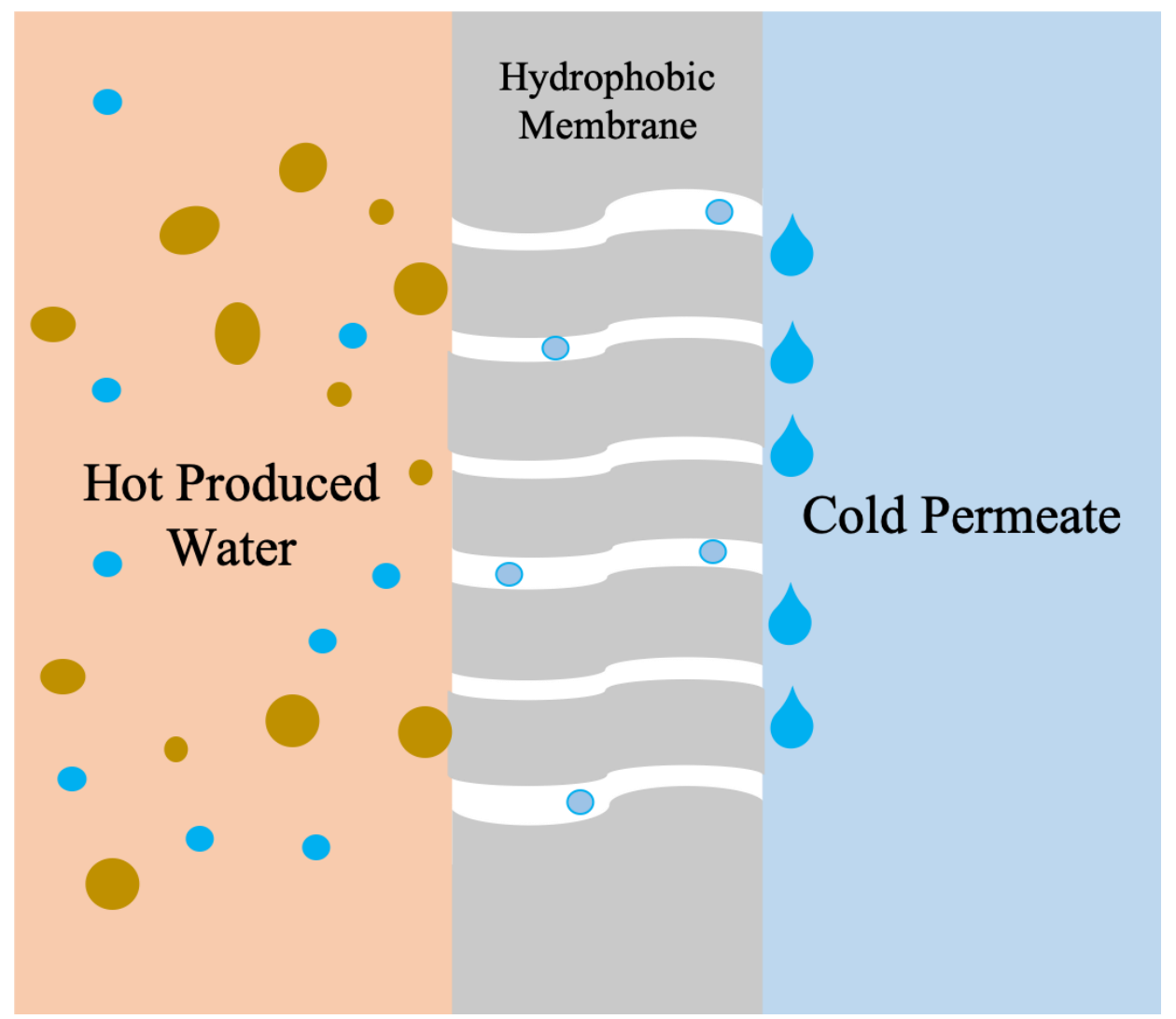

Figure 1. Schematic of membrane distillation 


\subsubsection{Fouling Mitigation}

Treating hydraulic fracturing PWs is challenging. Though MD provides satisfactory results for the treatment of high TDS synthetic wastewater, the large organic content of the hydraulic fracturing PW results in severe organic fouling of the hydrophobic membrane surface. Various techniques are used to mitigate membrane fouling such as feed pretreatment, backwashing, air sparging, and chemical cleaning. Pretreatment of water is a common practice before membrane filtration to reduce the suspended solids and dissolved organic matters, which results in suppressing the fouling [21]. Electrocoagulation (EC) is shown to be effective as a pretreatment method whereby conductive metal plates as electrodes corrode to release active metal ions into the solution $[22,23]$. The released metal ions further oxidize to neutralize particle charges and provide large surface areas to aggregate tiny colloids and dissolved organic compounds, and hence, organic pollutants precipitate as a sludge.

The following are the reactions happen at the anode and cathode after the voltage is applied [22]:

$$
\begin{aligned}
& \text { Anode: } M_{(s)} \rightarrow M_{(a q)}^{n+}+n e^{-} \\
& \text {Cathode: } \mathrm{H}_{2} \mathrm{O}+2 e^{-} \rightarrow \mathrm{H}_{2}+2 \mathrm{OH}^{-}
\end{aligned}
$$

where $\mathrm{M}$ is the electrode material. Released species can interact in solution in the following ways [24]:

1. Migration to the oppositely charged electrode and aggregation via charge neutralization.

2. Formation of a precipitate through the reaction of cation or hydroxyl ion $\left(\mathrm{OH}^{-}\right)$with the pollutant.

3. Formation of hydroxides through the reaction of metallic cation interacts with $\left(\mathrm{OH}^{-}\right)$; These metal hydroxides can bond to the pollutant (bridge coagulation). 
4. Formation of larger lattice-like structures and sweeping through the water (sweep coagulation).

5. Oxidation of pollutants to less toxic pollutants.

6. Removal through floating by bubbles.

$\mathrm{M}^{\mathrm{n}+}$ and $\mathrm{OH}^{-}$ions formed by the anode and cathode reactions produce monomeric metal species as follows with a dominancy determined by $\mathrm{pH}$ of the solution:

$$
x M_{(a q)}^{n+}+y O H^{-} \rightarrow M_{x}(O H)_{y}^{(x n-y)} \rightarrow x M(O H)_{n(s)}
$$

Charged hydrolyzed species attract charged organic compounds and suspended solids to form metal complexes by charge neutralization. Monomeric species can form polymeric complexes which eventually form amorphous $x M(O H)_{n(s)}$ with a large surface area. $x M(\mathrm{OH})_{n(s)}$ can trap organics pollutants and suspended solids. As the solution ages, metal complexes deposit and remove organic compounds and suspended solids from PW. Some lowdensity complexes rise to the top to the liquid air interface by adhesion to hydrogen bubbles produced at the cathode. These low-density complexes can densify and sediment to the bottom. These mechanisms create three zones: low-density flocs at the liquid-air interface; clear water at the middle region and aggregated flocs deposited at the bottom. The clear water from the middle zone can be separated [25]. Figure 2 illustrated the reactions during EC pretreatment. 


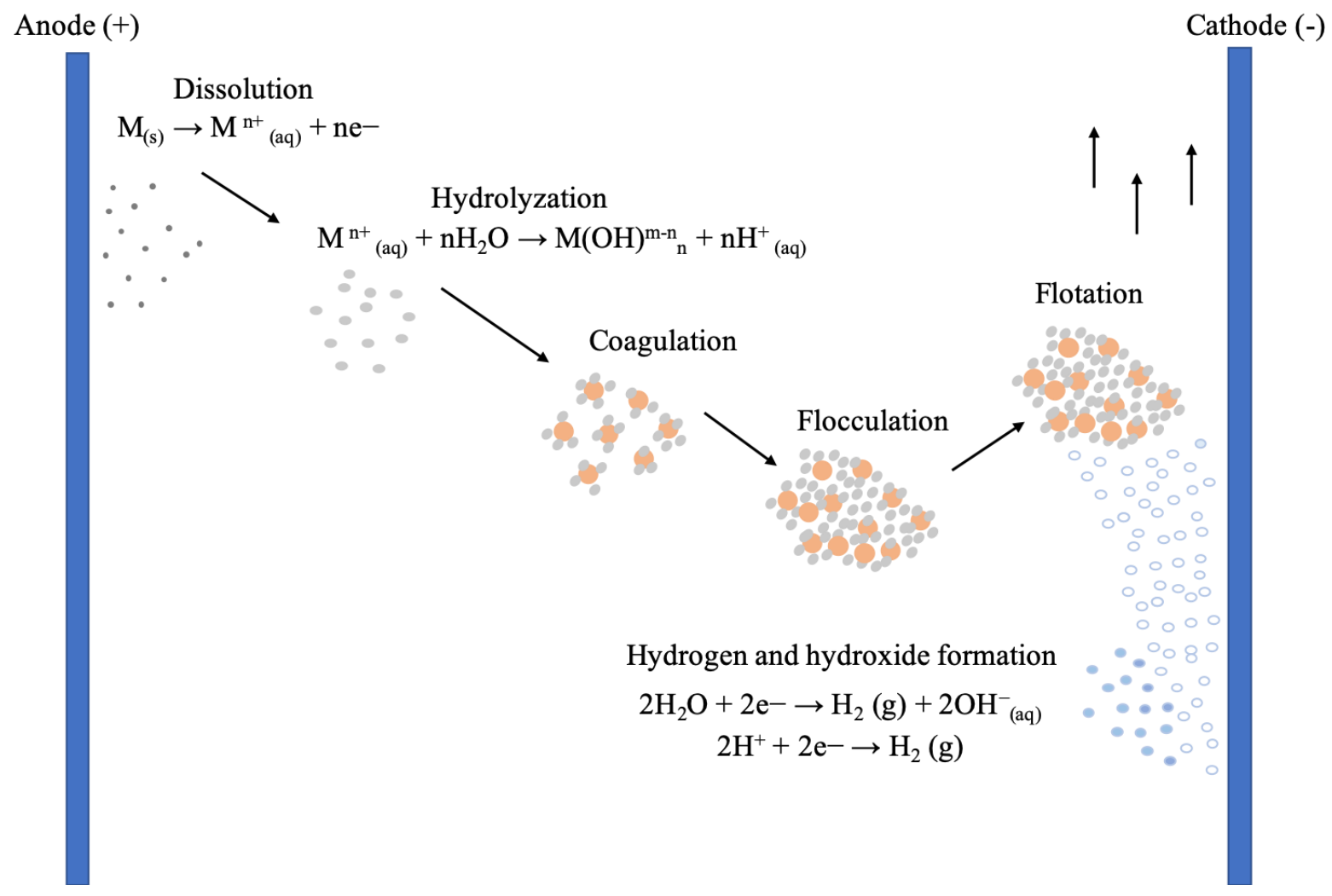

Figure 2. Schematic representation of reactions during EC pretreatment

However, dependency on electricity, demand for replacing electrodes, and the potential of oxide film formation on the cathode are the disadvantages of EC as a pretreatment method [26]. Modification of the membrane surface can be an alternative method to prevent severe organic fouling. An ideal membrane surface will be non-wetting in order to only allow water vapour transport through the membrane and suppress adsorption of polar and non-polar organic compounds, low surface tension compounds and suppress scale formation by dissolved salts.

Deshmukh et al. [27] have reviewed recent attempts to develop fouling resistant surfaces when treating PWs. Their review provides a summary of recent literature that attempts to modify hydrophobic membranes in order to suppress fouling. Surface wetting by a liquid depends on the liquid-air $\left(\gamma_{\mathrm{LA}}\right)$, solid-liquid $\left(\gamma_{\mathrm{SL}}\right)$ and solid-air $\left(\gamma_{\mathrm{SA}}\right)$ interfacial energy. For spreading of liquids 
$\gamma_{\mathrm{SA}-} \gamma_{\mathrm{SL}}>\gamma_{\mathrm{LA}}$

At equilibrium,

$\cos \theta=\frac{\gamma_{S A}-\gamma_{S L}}{\gamma_{L A}}$

where $\theta$ is the contact angle between the liquid and solid. For non-wetting surfaces with contact angles greater than $90^{\circ}$, the numerator of equation 5 should be negative. Omniphobic surfaces are ones with very low surface energy. However, lowering the surface energy of the surface will not suppress adsorption of low surface tension liquids for which wetting could still be thermodynamically favorable. Consequently, the membrane surface morphology should be tailored to provide a kinetic barrier to wetting by low surface tension compounds [28-30] However, development of a tailored membrane surface that can be manufactured economically at commercial scale is likely to be challenging.

An alternative approach involves modifying the membrane surface by grafting a thin nanostructure consisting of hydrophilic polymer chains that suppresses adsorption of organic species. However, care must be taken to ensure excessive scaling, and early breakthrough of the feed to the permeate side of the membrane is suppressed [31-33].

\subsection{Research Objectives}

In this work, we have investigated surface grafting on a commercially available base PVDF membrane as a route to increasing the membrane stability for MD of PW. Specifically, we have grafted hydroxyethyl methacrylate (HEMA), acrylic acid (AA), 1-vinyl-3-allylimidazolium bromide (Allyl) and 1-vinyl-3-hexylimidazolium bromide (Hexyl). Table 2 summarizes the monomers we have investigated. As these polymers contain both charged or hydrophilic groups as well as hydrophobic segments, we aim to suppress fouling by organic species while suppressing 
wetting of the membrane. HEMA has frequently been used to hydrophilize the membrane surface and hence suppress fouling by proteins and other organic species. AA is a weak acid that will be deprotonated at the $\mathrm{pH}$ of the PW. Consequently, the polymer chains will carry a net negative fixed charge. The two ionic liquids contain an imidazolium ion. Unlike AA, they will contain a repeating fixed charge (imidazolium ion) as well as hydrophobic segments along the polymer chain.

We have used DCMD to test base and modified membranes with PW. In addition, the membranes have been challenged with PW that has been pretreated by electrocoagulation. In our earlier studies $[22,23]$ we show that electrocoagulation may be used reduce the load of dissolved organic compounds in the PW. This leads to significantly improved membrane performance and stability. Thus, we compare results for the base and modified membrane challenged with PW and PW pretreated by EC using $\mathrm{Al}$ electrode. As an additional control, we have also conducted MD with a synthetic PW feed stream that contains the major inorganic species in the PW, dissolved in DI water. 
Table 2. Monomer structures and characteristics.

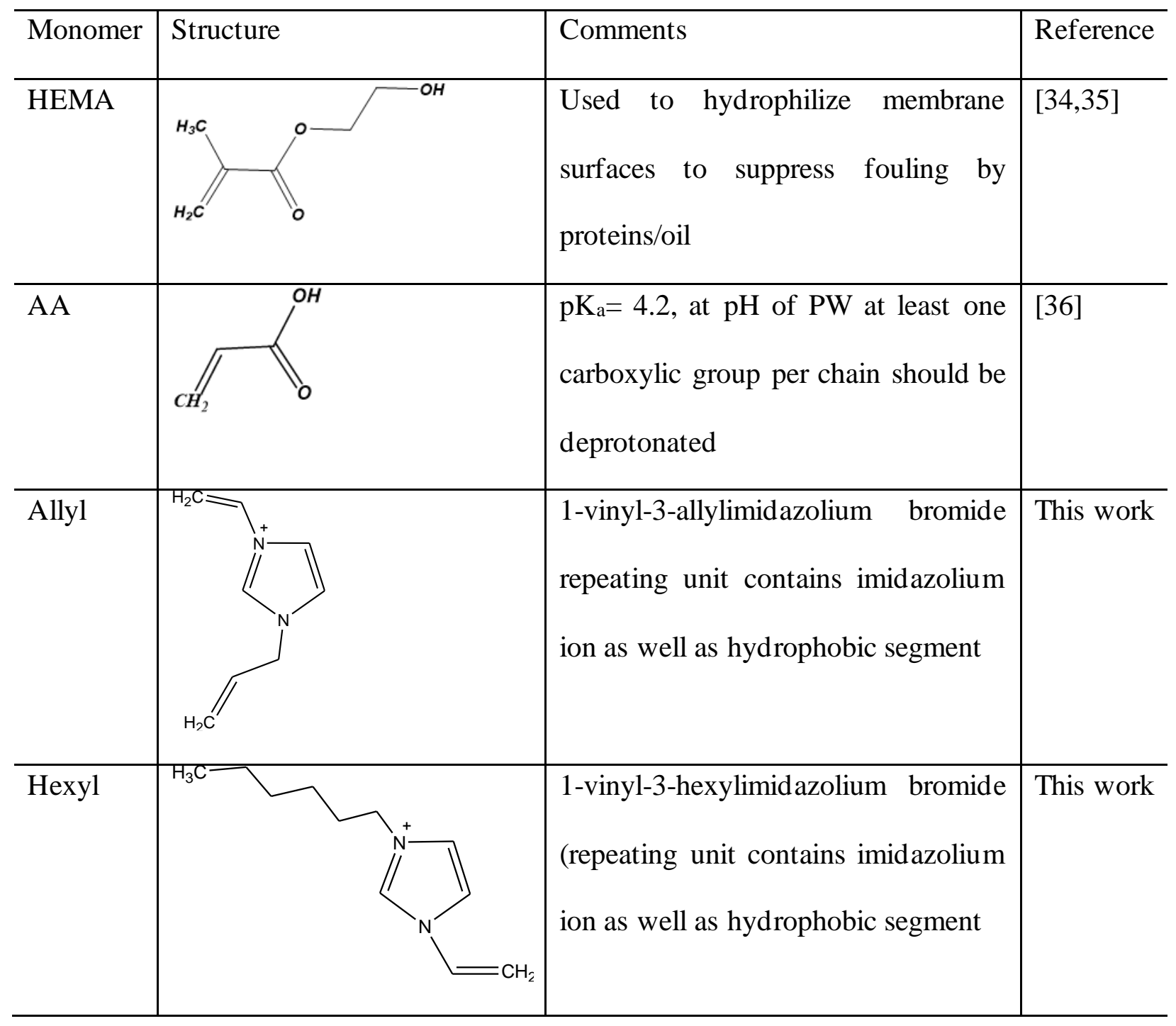

Following are the research objectives for this work.

Objective 1: Modify PVDF membranes through surface grafting to impose charged or hydrophilic groups on the membrane surface.

Objective 2: Conduct membrane distillation testing for the treatment of PW with the base and modified membranes with and without EC pretreatment. 
Objective 3: Analyze the performance of base and modified membranes treating pretreated and non-pretreated PW.

\subsection{Material and Methods}

\subsubsection{PW characterization}

Hydraulic fracturing PW was obtained from Southwestern Energy sites in West Virginia. The actual PW was characterized for total dissolved solid (TDS), total suspended solids (TSS), turbidity and total organic carbon (TOC) at the Arkansas Water Resources Center (Fayetteville, AR). TDS, TSS, TOC, and turbidity were measured using EPA standard methods 160.1, 160.2, 415.1, and 180.1 [37], respectively. Cations and anions were measured using EPA methods 200.7 and 300.0, respectively.

In addition, experiments were conducted using a synthetic PW that simulated the TDS of the PW in the absence of organic contaminants. In this way, the effect of the organic contaminants on membrane fouling could be determined for the base and modified membranes. The synthetic PW was prepared by dissolving sodium chloride $(1.69 \mathrm{~mol} / \mathrm{L})$ and calcium chloride $(0.59 \mathrm{~mol} / \mathrm{L})$ in deionized water (see Table 4).

\subsubsection{Materials}

Membrane samples were provided by MilliporeSigma (Billerica, MA). Hydrophobic PVDF membranes with $0.1 \mu \mathrm{m}$ nominal pore size were used in this study. Table 3 summarizes the membrane properties measured in our earlier publication [15]. 
Table 3. Membrane characteristics.

\begin{tabular}{llllll}
\hline Membrane & Porosity & $\begin{array}{l}\text { Thickness } \\
(\mu \mathrm{m})\end{array}$ & $\begin{array}{l}\text { Nominal pore size } \\
(\mu \mathrm{m})\end{array}$ & Tortuosity & LEP $(\mathrm{kPa})$ \\
& & & & & \\
\hline PVDF & 0.69 & 91 & 0.1 & 3.02 & 580 \\
\hline
\end{tabular}

Benzophenone and acrylic acid (AA) were procured from Acros Organics, Morris, NJ. 2hydroxyethylmethacrylate (HEMA, 97\%, stabilized with 4-methoxyphenol) was purchased from Alfa-Aesar, Ward Hill, MA. Methanol was purchased from Sigma Aldrich, St. Louis, MO. Deionized (DI) water used throughout the investigation was collected from Thermo Fisher $18 \mathrm{M} \Omega$ Barnstead Smart2Pure system, Schwerte, Germany. Vinyl imidazole, bromohexane and allyl bromide were purchased from Sigma Aldrich, St. Louis, MO.

\subsubsection{Synthesis of ionic liquids}

The synthesis of the ionic liquid monomers was by chemical reaction of vinyl imidazole with two different alkyl halides (bromohexane and allylbromide). Further details are also given in our previous publication [38]. Bromhexane or allylbromide was placed with vinyl imidazole in a glass container at an equal concentration of $0.025 \mathrm{M}$. The mixture was stirred at $60{ }^{\circ} \mathrm{C}$ for $3 \mathrm{~h}$. Phase separation of the straw yellow liquid confirmed the synthesis of the ionic liquid. The top phase was discarded as the supernatant and the yellow ionic liquid phase was subsequently washed with ethyl acetate to remove any unreacted precursor from the ionic liquid. 1-vinyl-3allylimidazolium bromide, and 1-vinyl-3-hexylimidazolium bromide were the resulting ionic liquids which were termed 'Allyl' and 'Hexyl', respectively. These ionic liquids were used without further purification. 


\subsubsection{Membrane surface modification procedure}

Surface modification of PVDF membranes was conducted using photo-initiated polymerization. Benzophenone was used as the photo initiator. The ground state benzophenone absorbs photons in the UV region [39]:

excitation: $\mathrm{BP}+\mathrm{h} v \rightarrow \mathrm{BP}^{*}$

where $\mathrm{BP}$ is benzophenone and * indicate the excited state. The photoreduction of benzophenone leads to the formation of a radical derived from the membrane surface as the hydrogen donor substrate and a radical produced from the carbonyl compound of benzophenone in the presence of hydrogen donors:

photoreduction: $\mathrm{BP}^{*}+\mathrm{P} \rightarrow \mathrm{P} \bullet+\mathrm{BP} \bullet$

where $\mathrm{P}$ is the membrane polymer and indicate the radical. The radicals derived from the hydrogen donors can react with the monomer to start the polymer chain grafting. However, membrane surface can either directly react with the monomer and initiate the polymerization or can undergo a coupling reaction with benzophenone radical:

$\mathrm{P} \bullet+\mathrm{BP} \bullet \rightarrow \mathrm{P}-\mathrm{BP}$

The UV irradiation can cleave the C-C bond between the membrane surface and benzophenone to form surface radicals allowing the initiation:

initiation: $\mathrm{P} \bullet+\mathrm{M} \rightarrow \mathrm{P}-\mathrm{M} \bullet$

where $\mathrm{M}$ is the monomer. Therefore, the chain will grow on the surface, and it will continue until the experiment is stopped or the polymerization termination occurs:

propagation: $\mathrm{P}-\mathrm{M} \bullet+\mathrm{nM} \rightarrow \mathrm{PM}_{\mathrm{n}} \mathrm{M} \bullet$

Chain termination can happen when a hydrogen atom is captured from the environment. In addition, chain coupling can also occur when two radicals on the chain end combine. 
Benzophenone radical also can either attach to a polymer chain and terminate the radical polymerization or react with another benzophenone radical present in the solution [40]:

termination: $\mathrm{P}-\mathrm{M}_{\mathrm{n}} \mathrm{M} \bullet+\mathrm{H} \bullet \rightarrow \mathrm{P}-\mathrm{M}_{\mathrm{n}+1} \mathrm{H}$

$\mathrm{P}-\mathrm{M}_{\mathrm{n}} \mathrm{M} \bullet+\mathrm{P}-\mathrm{M}_{\mathrm{n}} \mathrm{M} \bullet \rightarrow \mathrm{PM}_{n+1} \mathrm{M}_{\mathrm{n}+1} \mathrm{P}$

$\mathrm{P}-\mathrm{M}_{\mathrm{n}} \mathrm{M} \bullet+\mathrm{BP} \bullet \rightarrow \mathrm{PM}_{\mathrm{n}+1} \mathrm{BP}$

$\mathrm{BP} \bullet+\mathrm{BP} \bullet \rightarrow \mathrm{BP}-\mathrm{BP}$

Grafting yield of the polymer brush on the membrane surface using this method can depend on different factors such as the initiator concentration, monomer concentration, and UV irradiation time. Longer UV irradiation time and the higher concentration of monomer can produce longer and high-density polymer chains on the membrane surface. These dense polymer chains can increase mass transfer resistance across the membrane and cause membrane wetting by increasing the hydrophilicity of the membrane surface and membrane pores. Longer UV irradiation and higher monomer concentration can also facilitate the polymerization within the solution and hinder the desired surface grafting. Previous surface modification studies have shown successful grafting results using $1 \%$ wt. monomer concentration and 5 min UV irradiation time. Based on this knowled ge $1 \%$ wt. monomer solutions and 5 min grafting time were used in this study in order to graft a thin hydrophilic layer on the surface. Higher concentrations of initiator may ab sorb a higher percentage of the UV light hindering the polymerization. Prior studies have proven that $5 \%$ wt. of benzophenone is the ideal concentration for initiating the polymerization and has the optimum use of UV light [41]. Therefore, 5\% benzophenone solution was used in this study.

Commercially available PVDF membranes were cut into rectangles $(12.5 \times 7.5 \mathrm{~cm})$. The actual active membrane area of the module was $9 \times 4.5 \mathrm{~cm}$. The membranes were washed with a 
$50 \% \mathrm{v} / \mathrm{v}$ ethanol-water mixture and then rinsed with DI water before surface modification. A twostep membrane modification procedure was employed.

In the first step, the membranes were submerged in a benzophenone solution $(5 \mathrm{wt} . \%$ in methanol) for $5 \mathrm{~min}$ and were then dried at ambient temperature overnight. Since the PVDF membrane swells slightly in methanol, benzophenone can be trapped in the membrane structure as well as on the surface. In the second step, the membranes were immersed in an aqueous solution of monomer ( $1 \mathrm{wt} . \%)$ in the presence of UV radiation. The samples were exposed to UV radiation using a $160 \mathrm{~W}$ UV lamp for $5 \mathrm{~min}$. Finally, the membranes were rinsed numerous times with DI water and dried at room temperature overnight. Fig. 3 shows the schematic of the modification procedure. 


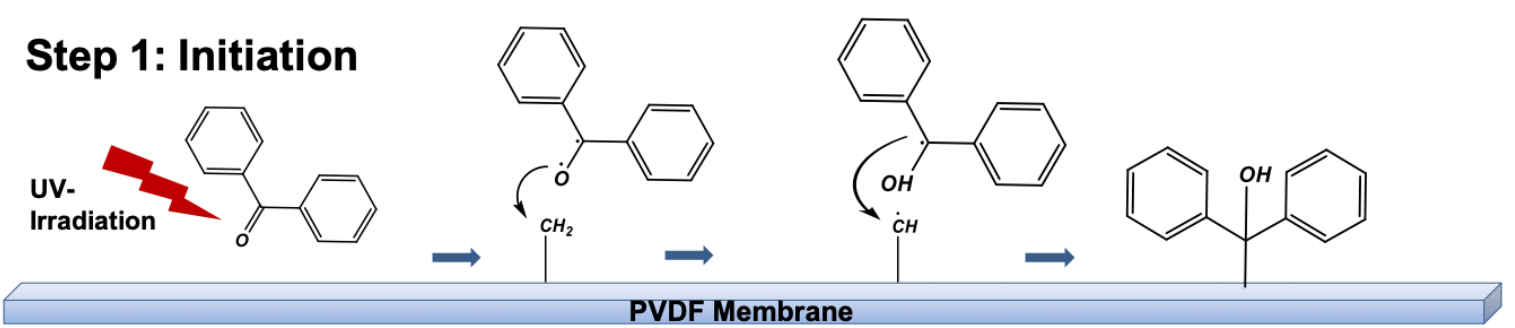

\section{Step 2: Polymerization with different monomers}
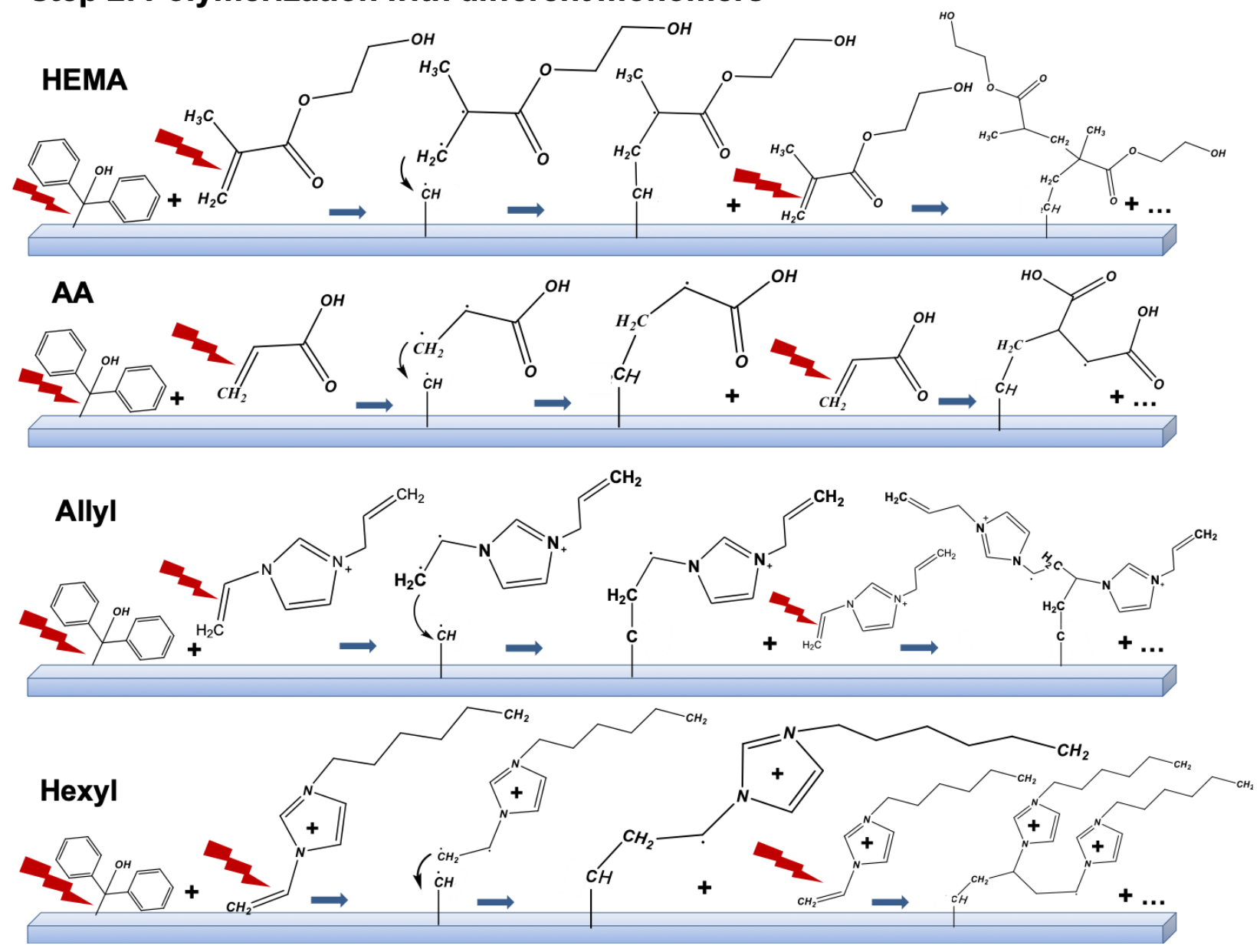

Figure 3. Surface grafting modification procedure.

\subsubsection{Characterization of modified membranes}

\subsubsection{Fourier-transform infrared (FTIR) spectroscopy}

FTIR spectroscopy was used for qualitative analysis of the functional groups on the membrane surface ( 2000 nm thick top layer) in order to verify surface modification had occurred. Samples were dried in a vacuum oven at $40^{\circ} \mathrm{C}$ for $2 \mathrm{~h}$ prior to analysis using IR Affinity (Shimadzu, 
Columbia, MD, USA) with a horizontal ZnSe accessary. FTIR spectra were averaged over 300 scans covering a range of 800 to $4000 \mathrm{~cm}^{-1}$.

\subsubsection{Contact angle}

A contact angle goniometer (Model 100, Rame-Hart Instrument Company, Netcong, NJ) was used to measure the static contact angle of the base and modified membranes in order to determine the change in contact angle after modification. A $5 \mu \mathrm{L}$ water droplet was formed on the membrane surface at a rate of $2 \mu \mathrm{L} \mathrm{s}^{-1}$. Left- and right-hand side contact angles were measured using the curve-fitting method and averaged over fifteen replicates.

\subsubsection{Scanning electron microscopy (SEM) and energy-dispersive X-ray (EDX) spectroscopy}

SEM was conducted using a Nova Nanolab 200 Duo-Beam SEM (FEI, Hillsboro, OR) to analyze the membrane surface before and after MD. The membrane samples were dried using a vacuum oven at $40^{\circ} \mathrm{C}$ and coated with a layer of gold ( $10 \mathrm{~nm}$ thick) prior to SEM imaging. The same equipment was used for EDX spectroscopy in order to determine the elements on the membrane surface.

\subsubsection{MD setup}

Fig. 4 gives a schematic diagram of the MD setup. As can be seen, a $1 \mathrm{~L}$ feed tank was placed over a hot plate. Feed water was stirred and maintained at $60^{\circ} \mathrm{C}$. One liter of DI water was placed in a permeate tank which in turn was placed on a computer-connected analytical balance (Mettler Toledo, Columbus, $\mathrm{OH}$ ) and maintained at $20^{\circ} \mathrm{C}$ using an external chiller (PolyScience, Niles, IL). The permeate conductivity was continuously monitored using a conductivity meter 
(VWR, Radnor, PA). If the permeate conductivity increased above $50 \mu \mathrm{S} \mathrm{cm}^{-1}$, it was assumed that pore wetting had occurred, and feed water had passed into the permeate.

A custom-made polycarbonate membrane module with an approximate effective surface area of $40 \mathrm{~cm}^{2}$ was used. Polypropylene spacers (XN4510, Industrial Netting, Minneapolis, MN) were used to fill the $2 \mathrm{~mm}$ deep channels on the feed and permeate sides of the module and to provide mechanical support for the membrane. Feed and permeate streams were pumped on opposite sides of the membrane at $0.5 \mathrm{~L} \mathrm{~min}^{-1}$ using two peristaltic pumps (Masterflex I/P, Cole Parmer, Vernon Hills, IL). The water flux was calculated based on the rate of weight change in the permeate tank. For the base membrane, experiments were conducted till the membrane failed (conductivity increased above $50 \mu \mathrm{S} \mathrm{cm} \mathrm{cm}^{-1}$ ). For modified membranes, the experiments were conducted till the flux dropped below $6 \mathrm{~L} \mathrm{~m}^{-2} \mathrm{~h}^{-1}$. Modified membranes were regenerated and challenged with another batch of PW. The regeneration cycle consisted of pumping DI water at $0.5 \mathrm{~L} \mathrm{~min}^{-1}$ on both sides of the membrane for 1 hour. Then, MD was conducted again. 


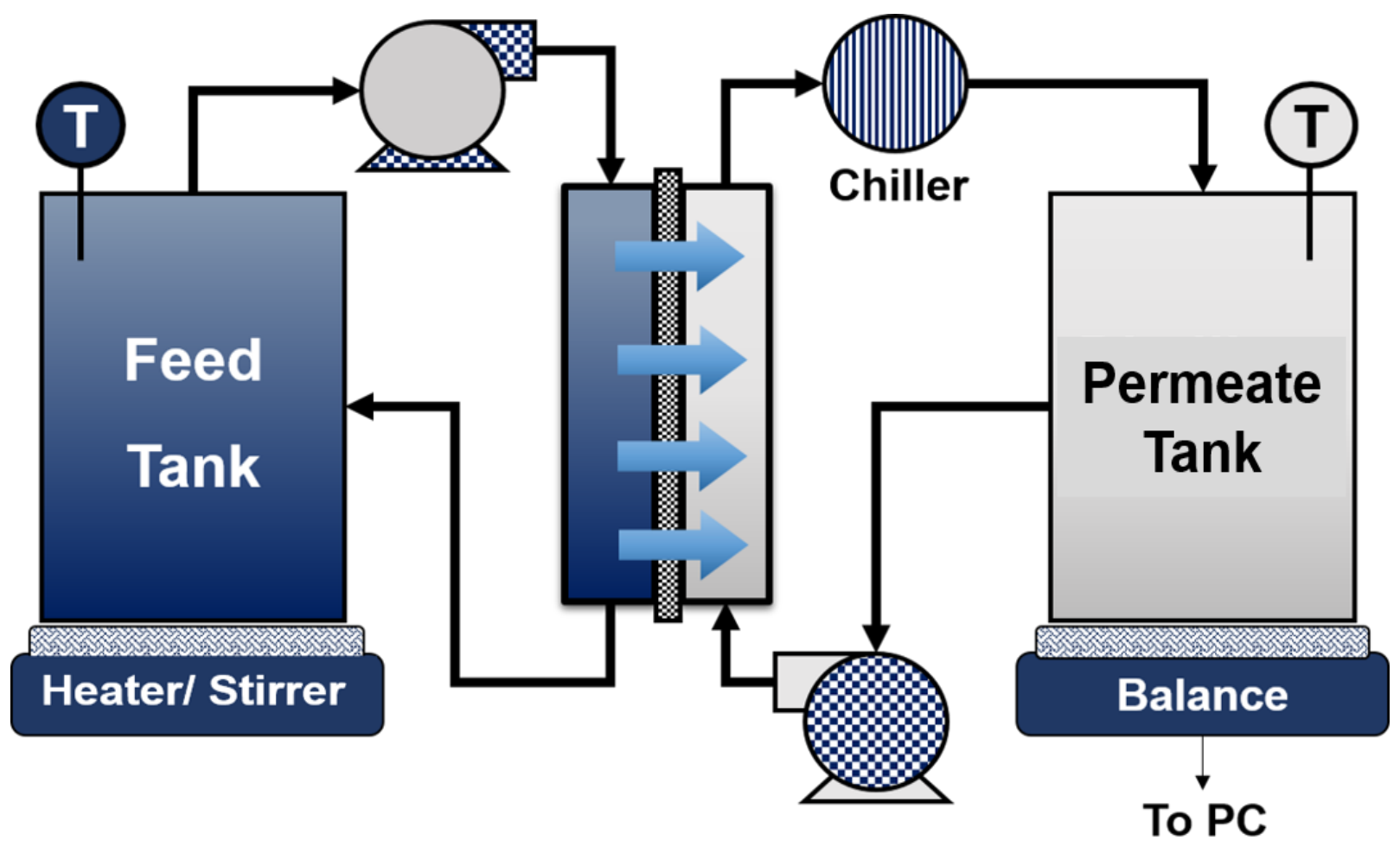

Figure 4. Schematic diagram of MD set up.

\subsubsection{Electrocoagulation setup}

Based on our earlier results [22], electrocoagulation was used as a pretreatment step in order to compare fouling of the membranes when most of the organic contaminants had been removed from the $\mathrm{PW}$ with non-pretreated $\mathrm{PW}$. During electrocoagulation, $\mathrm{Al}^{3+}$ and $\mathrm{OH}^{-}$ions are produced at anode and cathode, respectively. The reaction between $\mathrm{Al}^{3+}$ and $\mathrm{OH}^{-}$ions results in the production of different polymeric species such as: $\mathrm{Al}_{6}(\mathrm{OH})_{15^{3+}}, \mathrm{Al}_{8}(\mathrm{OH})_{20} 0^{4+}$ and $\mathrm{Al}_{13}(\mathrm{OH})_{34^{5+}}$ [42]. However, in the $\mathrm{pH}$ range of 4 to 10 , the formation of insoluble $\mathrm{Al}(\mathrm{OH})_{3}$ pred ominates [43]. The $\mathrm{pH}$ of the $\mathrm{PW}$ was in this range. These amorphous particles have a large surface area favorable for adsorption of soluble organic compounds or trapping colloidal particles [44]. Removal efficiencies were calculated using the following equation: 
Removal Efficiency $(\%)=\frac{C_{P W}-C_{\text {pretreated } P W}}{C_{P W}}$

where, $C_{P W}$ and $C_{\text {pretreated }} P W$ are the concentration of the wastewater parameter in the PW before and after electrocoagulation, respectively. Electrocoagulation was carried out in a $1 \mathrm{~L}$ polycarbonate reactor, employing 5 blades (6061 aluminum alloy, Sapa, Rosemont, IL) with 180 $\mathrm{cm}^{2}$ effective surface area. All experiments were run in batch mode. The outlets of a DC power source (Hewlett Packard, Palp Alto, CA) were connected to the first and last electrodes inside the reactor, providing the required electrical current. Based on the conditions reported by Sardari et al. [22], the voltage was maintained at $20 \mathrm{~V}$. After a 30 second reaction time, the PW was transferred to a separatory funnel for phase separation. After $6 \mathrm{~h}$ sedimentation, low density flocs that floated at the surface were removed as were dense flocs that settled to the bottom.

\subsection{Results and discussion}

\subsubsection{Wastewater characterization}

Table 4 gives the water quality analysis for the PW and PW after electrocoagulation. As can be seen, the PW contains $157,000 \mathrm{mg} \mathrm{L}^{-1} \mathrm{TDS}, 1,277 \mathrm{mg} \mathrm{L}^{-1} \mathrm{TSS}$, and $11.9 \mathrm{mg} \mathrm{L}^{-1} \mathrm{TOC}$. The water has also been analyzed in terms of inorganic content. As can be seen in Table 4, sodium and calcium account for the majority of the cations, while the main anion is chloride. In addition, the PW contains 1,248 and $75.5 \mathrm{mg} \mathrm{L}^{-1}$ magnesium and sulfate, respectively. While the hydrophobic base PVDF membrane will effectively suppress scaling by dissolved salts, the dissolved organic species can adsorb on the membrane surface, which will lead to flux decline and eventually membrane wetting. 
Table 4. Water quality analysis for PW and PW after electrocoagulation

\begin{tabular}{cccc}
\hline Parameter & Unit & PW & $\begin{array}{c}\text { PW after } \\
\text { electrocoagulation }\end{array}$ \\
\hline TDS & $\mathrm{mgL}^{-1}$ & 157,000 & 153,995 \\
TSS & $\mathrm{mg} \mathrm{L}^{-1}$ & 1,277 & 207 \\
TOC & $\mathrm{mg} \mathrm{L}^{-1}$ & 11.9 & 3.1 \\
Turbidity & $\mathrm{NTU}^{\prime}$ & 273 & 29.8 \\
Calcium & $\mathrm{mg} \mathrm{L}^{-1}$ & 18,042 & 17,739 \\
Chloride & $\mathrm{mg} \mathrm{L}^{-1}$ & 102,200 & 100,005 \\
Magnesium & $\mathrm{mg} \mathrm{L}^{-1}$ & 1,248 & 1,076 \\
Sodium & $\mathrm{mg} \mathrm{L}^{-1}$ & 38,780 & 35,181 \\
Sulfate & $\mathrm{mg} \mathrm{L}^{-1}$ & 75.5 & 20.7 \\
pH & & 6.4 & 6.7 \\
\hline Electroneutrality percent & $\%$ & $<5$ & $<5$ \\
difference & & & \\
\hline
\end{tabular}

\subsubsection{Modification of hydrophobic PVDF membrane}

In the first step, the initiator, benzophenone, is adsorbed onto the membrane surface. Next, the membrane is placed in the monomer solution. In the presence of UV radiation, the carboxyl group present in the benzophenone will abstract a hydrogen atom from the PVDF membrane leading to the generation of radicals on the membrane. These radicals will attack the $\pi$ bonds of the monomer. Hemolytic cleavage of the $\pi$ bond results in the formation of covalent bonds between the PVDF membrane and the monomer, leaving a carbon based radical on the monomer. This 
radical can attack another monomer leading to chain propagation. Alternatively, chain termination occurs when a hydrogen atom is captured from the environment. In addition, chain coupling can also occur when two radicals on the chain end combine.

\subsubsection{Surface characterization of the modified membrane}

Fig. 5 shows FTIR spectra for the base and modified membranes. These spectra provide qualitative information on the surface groups present on the base and modified membranes. As can be seen, the base membrane showed only the signature of C-F and C-C bonds, which is very similar to the reports available in the literature for PVDFmembranes [45]. For the surface modified membranes, additional peaks were observed as a result of the grafted polymer chains. A broad peak 3400-3700 $\mathrm{cm}^{-1}$ was observed for HEMA and AA modified membranes and was attributed to the hydroxyl $(\mathrm{O}-\mathrm{H})$ group. The broadening of the peak is a signature of different extents of $\mathrm{H}$ bonding by the $-\mathrm{OH}$ groups present on the membrane surface [46]. The peak $\sim 1735 \mathrm{~cm}^{-1}$ was attributed to the carbonyl groups from HEMA and AA modified membranes. The peak positions for the carbonyl groups present in HEMA and AA modified membranes were found to be slightly different. This is due to the fact that the carbonyl group for the HEMA modified membrane is of ester origin, while for the AA modified membranes it is of carboxylic origin.

For both the ionic liquid modified membranes, 2 partially resolved peaks, the signature of the imidazolium stretching frequency, were found to be prominent [37]. 


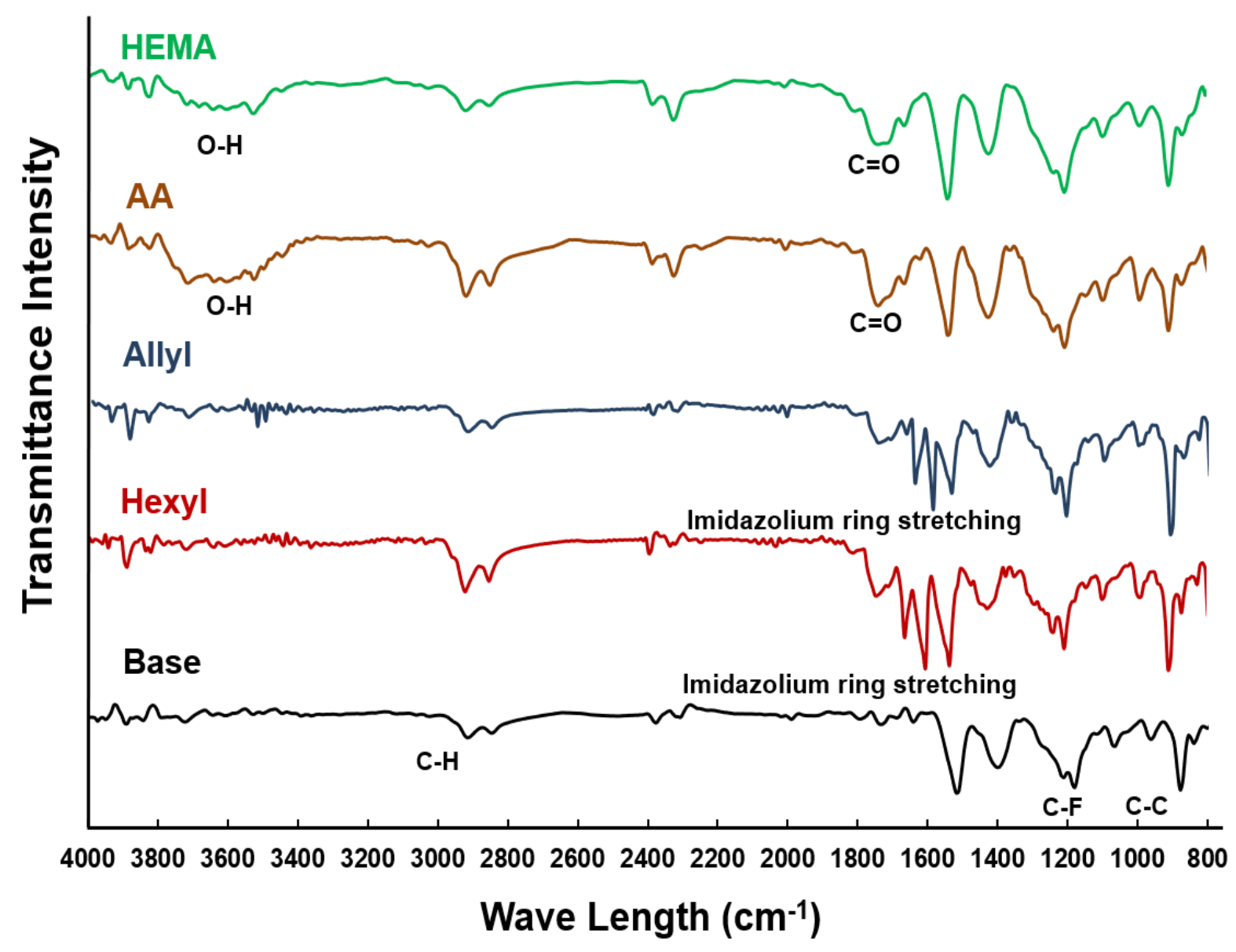

Figure 5. FTIR spectra of the base and modified PVDF membranes.

Table 5 summarizes the contact angles for the base and modified membranes. The base PVDF membrane showed a contact angle of $\sim 140^{\circ}$, indicating the hydrophobic surface of the base membrane. As can be seen, the contact angles for all modified membranes decreased compared to the base membrane, though they are all higher than $90^{\circ}$. The measured contact angle for HEMA and AA modified PVDF membranes were $\sim 126$ and $\sim 125$ degrees, respectively. Ionic liquid modified membranes (Allyl and Hexyl) displayed the same contact angle, within experimental error. In fact, all modified membranes display the same contact angle within experimental error.

As can be seen, the contact angles for all modified membranes decreased compared to the base membrane. This is due to grafting a nanostructure that displays a lower surface contact angle 
than the base PVDF membrane. Importantly for the modified membranes, the surface contact angle remains higher than $90^{\circ}$, which indicates that the membrane surface is still hydrophobic. This is essential for MD membranes in order to suppress membrane wetting, which will lead to water passage through the membrane pores.

Table 5. Base and modified membrane contact angles

\begin{tabular}{lcccc}
\hline \multirow{2}{*}{ Base membrane } & \multicolumn{4}{c}{ Modified membrane } \\
\cline { 2 - 5 } & HEMA & AA & Allyl & Hexyl \\
$140 \pm 2$ & $126 \pm 3$ & $125 \pm 4$ & $121 \pm 2$ & $120 \pm 3$ \\
\hline
\end{tabular}

\subsubsection{MD performance}

Membranes were challenged with PW, PW after electrocoagulation and synthetic PW. Fig. 6 shows the percentage removal of TDS, TSS, TOC, and turbidity after electrocoagulation (see also Table 4). As can be seen, TSS, TOC, and turbidity were removed by $\sim 84, \sim 75$ and $\sim 89 \%$, respectively. Thus, pretreated PW has a very low load of dissolved organic compounds. 


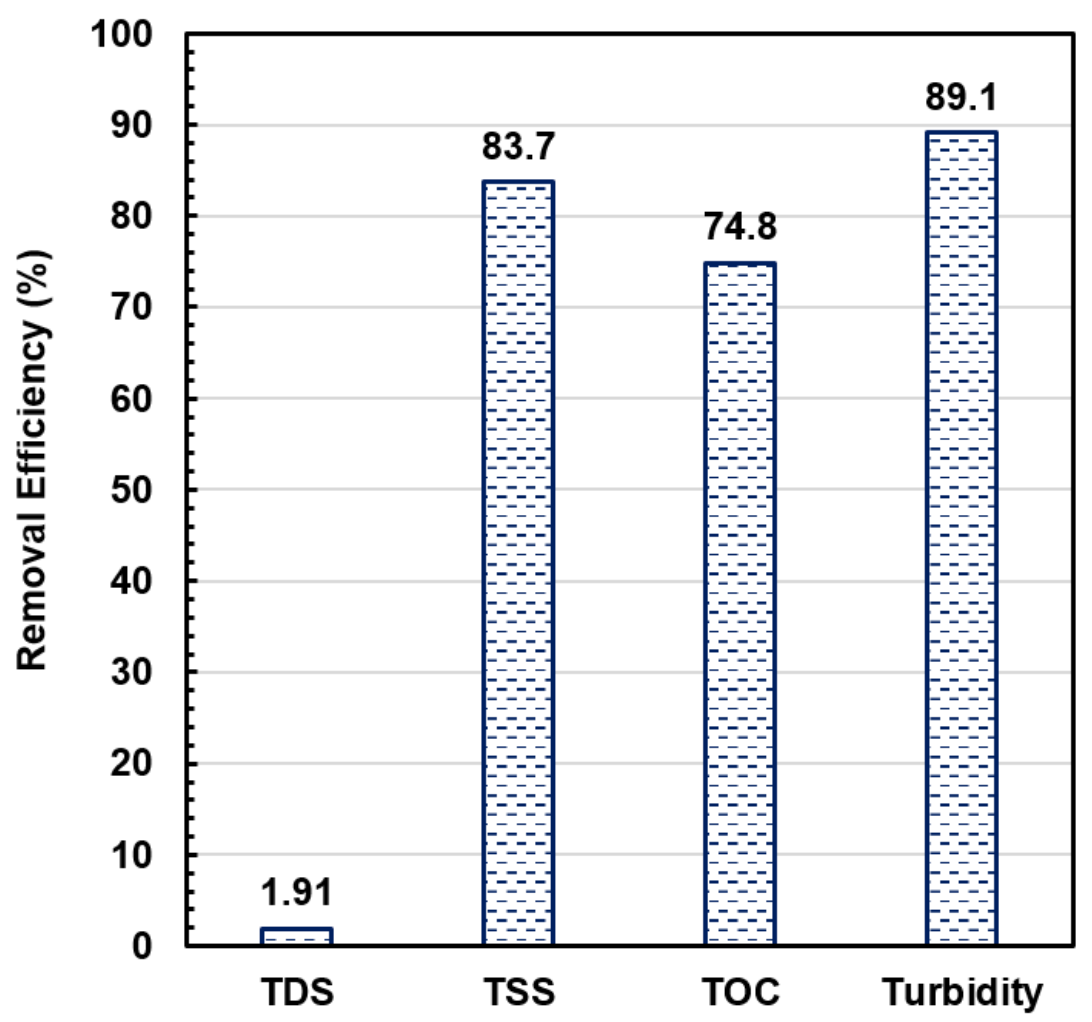

Figure 6. Percentage removal of TDS, TSS, TOC and turbidity during electrocoagulation of PW.

\subsubsection{Initial permeate flux}

Fig. 7 gives the initial permeate flux for the base and modified membranes. The initial flux is the average flux over the first 10 min of operation. All membranes were challenged with PW. In addition, the base and Allyl modified membranes were challenged with the synthetic and pretreated PW. As can be seen for the same feed stream, the base membrane always displayed a higher initial flux than the modified membranes. This is not unexpected as grafting a nanostructure from the membrane surface will lead to an additional resistance to permeate flow. It is, however unlikely that significant grafting occurred within the membrane pores. UV initiated grafting is confined to the membrane surface due to limited penetration of UV radiation into the bulk

membrane structure. The initiator immobilization time and polymerization time were chosen to 
prevent high density grafting of 'long' chains. No change in pore size was observed by SEM analysis. Initial fluxes increased for the same membrane when challenged with PW, PW pretreated by electrocoagulation and synthetic $\mathrm{PW}$, respectively. The result indicates that the presence of dissolved organic compounds has a significant effect on membrane performance.

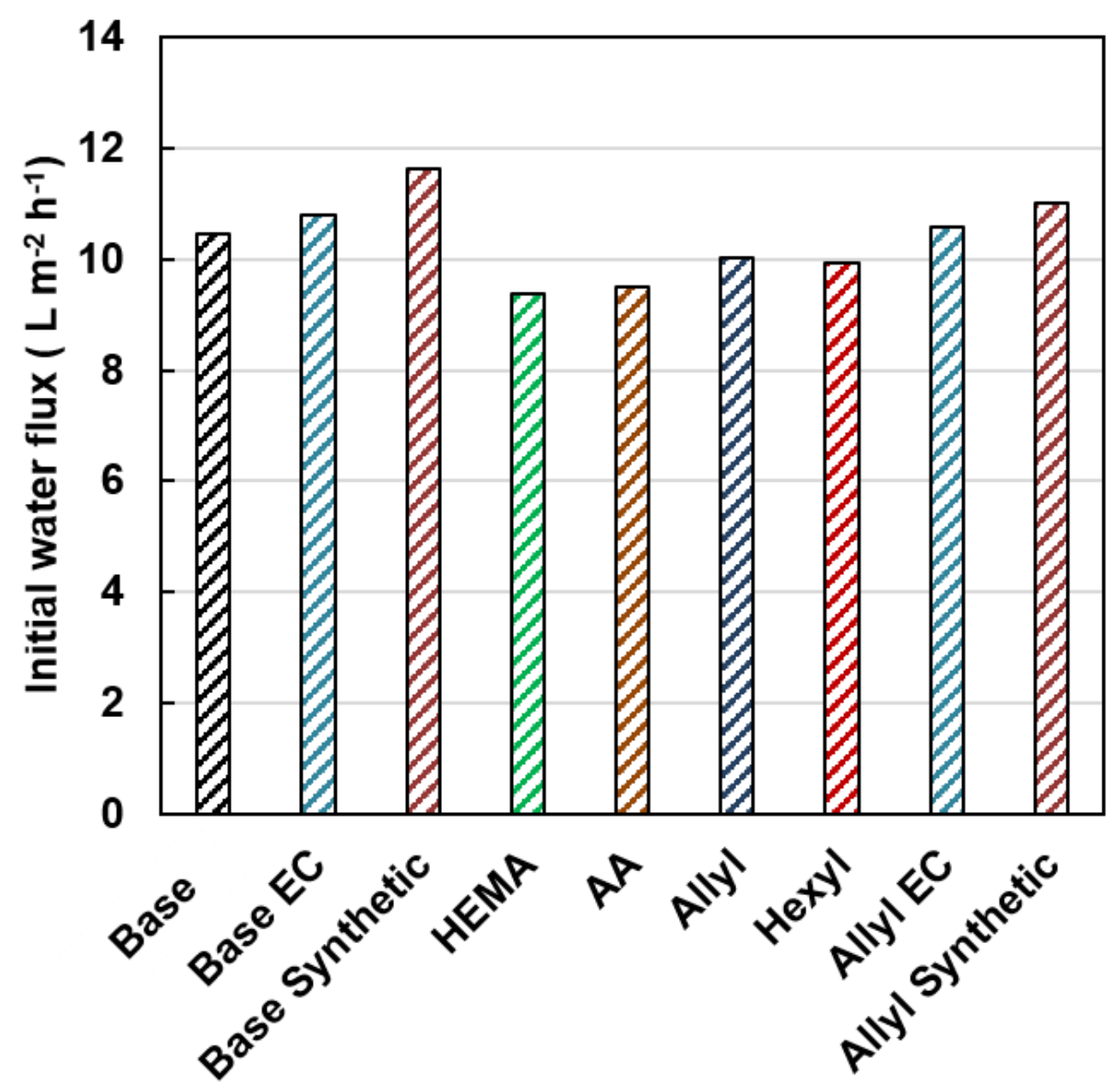

Figure 7. Initial water flux for base and modified membranes. Membranes were challenged with $\mathrm{PW}$ except where noted. $\mathrm{EC}=\mathrm{PW}$ pretreated by electrocoagulation, Synthetic $=$ synthetic $\mathrm{PW}$.

\subsubsection{Base membrane results}

Fig. 8 shows the normalized water flux for the base membrane as a function of permeate volume. The normalized flux was calculated as:

$$
\text { Normalized flux }=\frac{J}{J_{0}}
$$


where, $J$ is the measured flux and $J_{0}$ the initial flux given in Figure 7. All experiments were continued until the conductivity of the permeate stream rose rapidly above $50 \mu \mathrm{S} \mathrm{cm}-1$. Thus, for all three feed streams pore wetting occurred. As can be seen in Fig. 8, the water flux declines for all three feed streams. The flux decline is greatest for the PW and least for the synthetic PW. The maximum water recovery was for the synthetic PW and least for the PW. In all cases, the maximum water recovery was less than 50\%. Comparing Figure 7 and 8 , at breakthrough, the water flux was a little less than $6.0 \mathrm{~L} \mathrm{~m}^{-2} \mathrm{~h}^{-1}$. Membrane failure occurred at a TDS of $\sim 262 \mathrm{~g} \mathrm{~L}^{-1}$, $\sim 276 \mathrm{~g} \mathrm{~L}^{-1}$ and $295 \mathrm{~g} \mathrm{~L}^{-1}$ for PW, PW pretreated by electrocoagulation and synthetic PW, respectively. The results highlight the effect of dissolved organic compounds on membrane performance.

Fig. 9 gives SEM images and elemental analysis results from EDX spectroscopy after MD (same membranes used in Figure 8). The SEM images suggest qualitatively that deposition on the membrane surface is greatest for PW and least for synthetic PW. As can be seen from the EDX spectra, carbon and fluorine peaks are observed on all membranes as expected for PVDF [47]. Hydrogen cannot be detected by EDX spectroscopy. A significant reduction in the intensity of the fluorine peak for PW (see Figure 9.d) compared to that of pretreated and synthetic PW (see Figures 9.e and 9.f) was attributed to more severe ad sorption of dissolved species on the membrane surface.

The base membrane contributes to the observed carbon peak. However, unlike the fluorine peak, the carbon peak is enhanced for MD with PW and is least for the membrane challenged with synthetic PW. The increase in the peak is due to fouling by organic compounds. The presence of a prominent oxygen peak for the membrane challenged with PW and a much smaller peak for pretreated PW further supports this conclusion. 
In addition, peaks for the various inorganic species are also observed. The gold peak is due to the surface coating that is deposited prior to analysis. For the membrane challenged with PW and pretreated PW, the other inorganic species correspond to the dissolved species present in the PW (see table 4). In the case of synthetic PW, only $\mathrm{Na}, \mathrm{Ca}$, and $\mathrm{Cl}$ are present as confirmed by Figure 9.f. The Al peak for pretreated PW is probably due to the electrocoagulation step. Taken together, these results indicate that both organic and inorganic species adsorb onto the PVDF surface. However, the presence of dissolved organic species has a negative effect on membrane performance. It leads to more rapid flux decline and earlier membrane failure due to wetting.

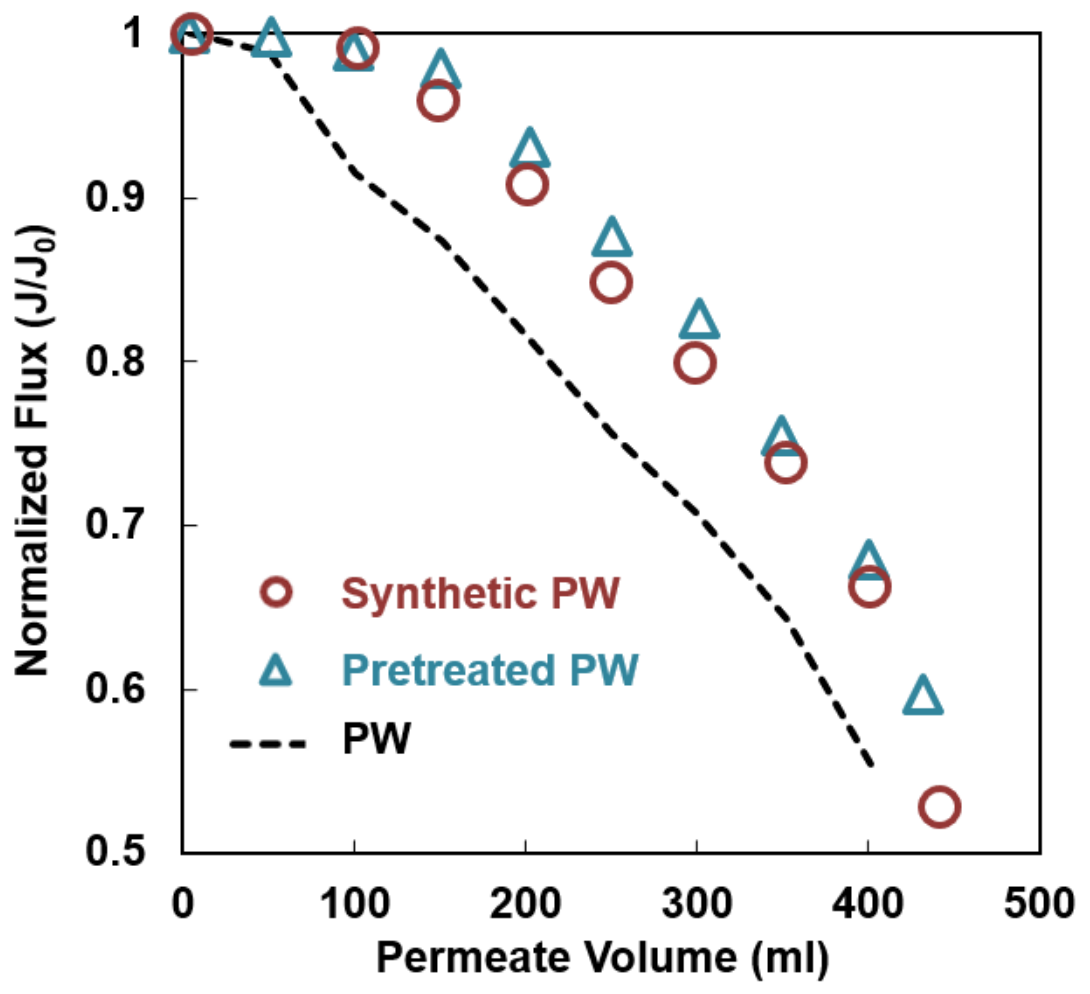

Figure 8. Normalized water flux for base membrane challenged with PW, pretreated PW and synthetic PW. 
a)

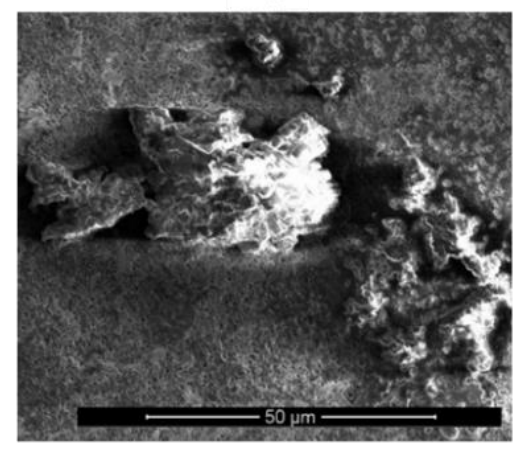

c d)

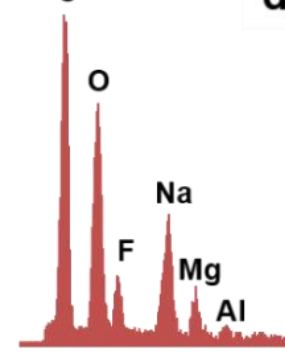

0.1 d)

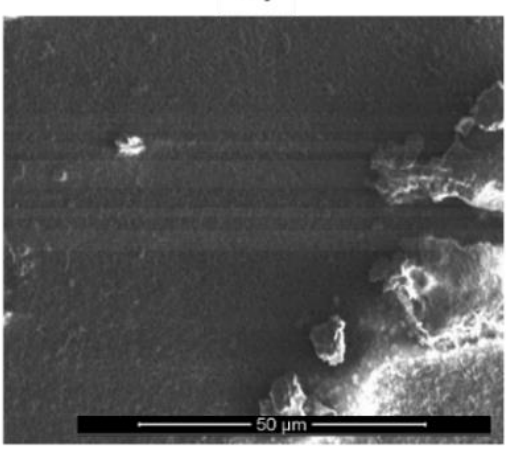

e) c)

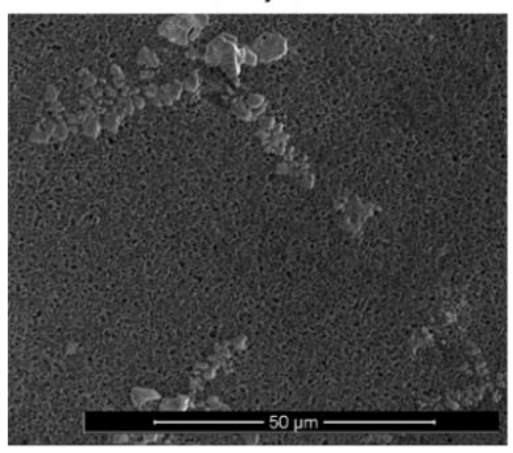

f)

Figure 9. SEM images and EDX spectroscopy results for base membrane after MD with a and d) $\mathrm{PW}, \mathrm{b}$ and e) pretreated $\mathrm{PW}$ and $\mathrm{c}$ and f) synthetic PW.

\subsubsection{Modified membrane results}

If pore wetting occurs, membrane regeneration is extremely difficult. Thus, MD should be stopped, and regeneration commenced prior to pore wetting. Based on the results for the base membranes, all modified membranes were run till the flux dropped below $6.0 \mathrm{~L} \mathrm{~m}^{-2} \mathrm{~h}^{-1}$. Fig 10 gives the normalized water flux for modified membranes when challenged with PW. Figure 10.a gives results for the HEMA and AA modified membranes, while Figure 10.b gives results for the polyionic liquid modified membranes. Results for the base membrane challenged with PW are included as a dashed line. By stopping MD when the flux d ropped below $6.0 \mathrm{~L} \mathrm{~m}^{-2} \mathrm{~h}^{-1}$, membrane failure was avoided. As can be seen for all the modified membranes, the water recovery (permeate 
volume) was higher than for the base membrane before the flux dropped to below $6.0 \mathrm{~L} \mathrm{~m}^{-2} \mathrm{~h}^{-1}$. The water recovery was similar for the HEMA and AA modified membranes. It was similar but higher for the polyionic liquid modified membranes.

a)

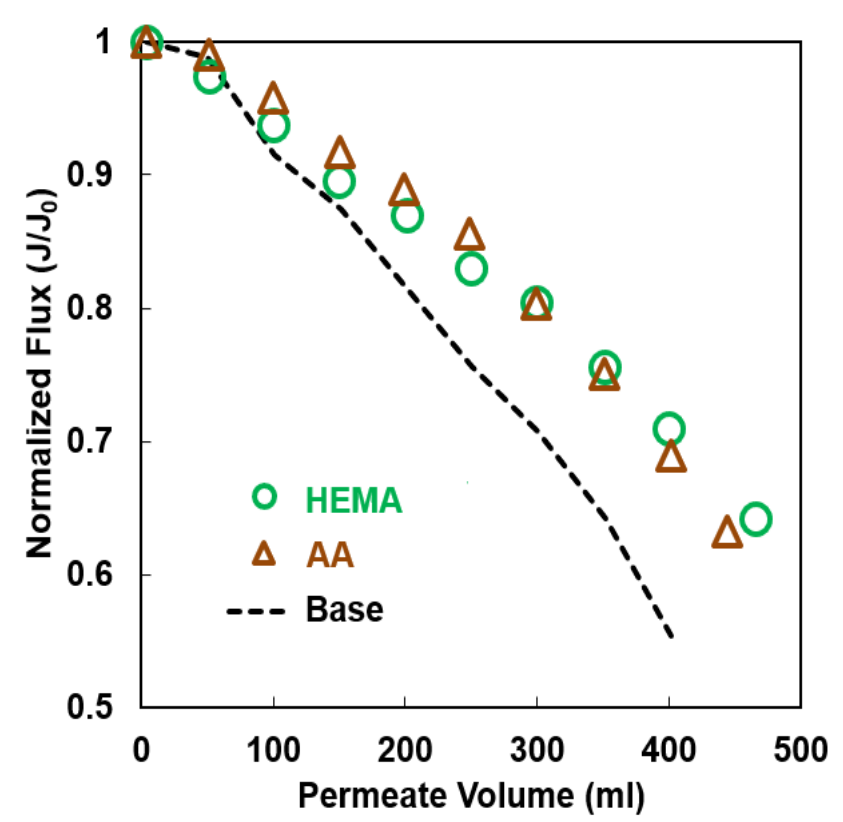

b)

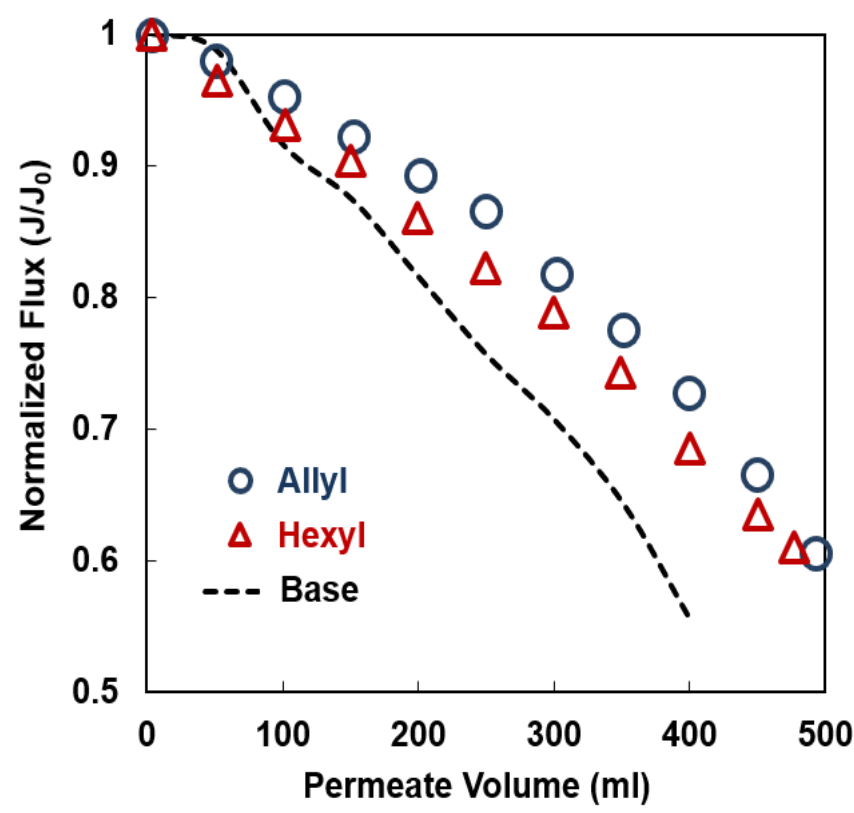

Figure 10. Normalized water flux for a) HEMA, AA, and b) polyionic liquids modified membranes. The feed consisted of PW, results for the base membrane are also included (dashed line).

After the flux dropped below $6.0 \mathrm{~L} \mathrm{~m}^{-2} \mathrm{~h}^{-1}$, MD was stopped, and the membranes regenerated. MD was then recommenced with a new batch of PW feed. This cycle was repeated twice. The variation of flux with cumulative permeate volume is given in Fig. 11. In order to clearly observe decreases in the initial flux after regeneration, the actual flux rather than the normalized flux is given in Figure 11. Figure 11.a gives results for the HEMA and AA modified membranes while Figure 11.b give results for the polyionic liquid modified membranes. 
The results in Figure 11 indicate that all membranes could be regenerated when the flux dropped below $6.0 \mathrm{~L} \mathrm{~m}^{-2} \mathrm{~h}^{-1}$ and reused. The water recovery is less than $50 \%$ (cumulative permeate volume should be $1.5 \mathrm{~L}$ for $50 \%$ recovery). The water recovery for the HEMA and AA modified membranes is similar. For each subsequent cycle, though the initial flux is close to the initial flux of the virgin membrane, the initial flux for all membranes is lower. This indicates that there are strongly adsorbed species on the membrane surface that are not removed by the regeneration procedure used here, which consisted of flushing with DI water for 1 hour. The polyionic liquid modified membranes display higher water recovery than the HEMA and AA modified membranes. The water recovery for the Allyl modified membrane is higher than the Hexyl modified membrane. 

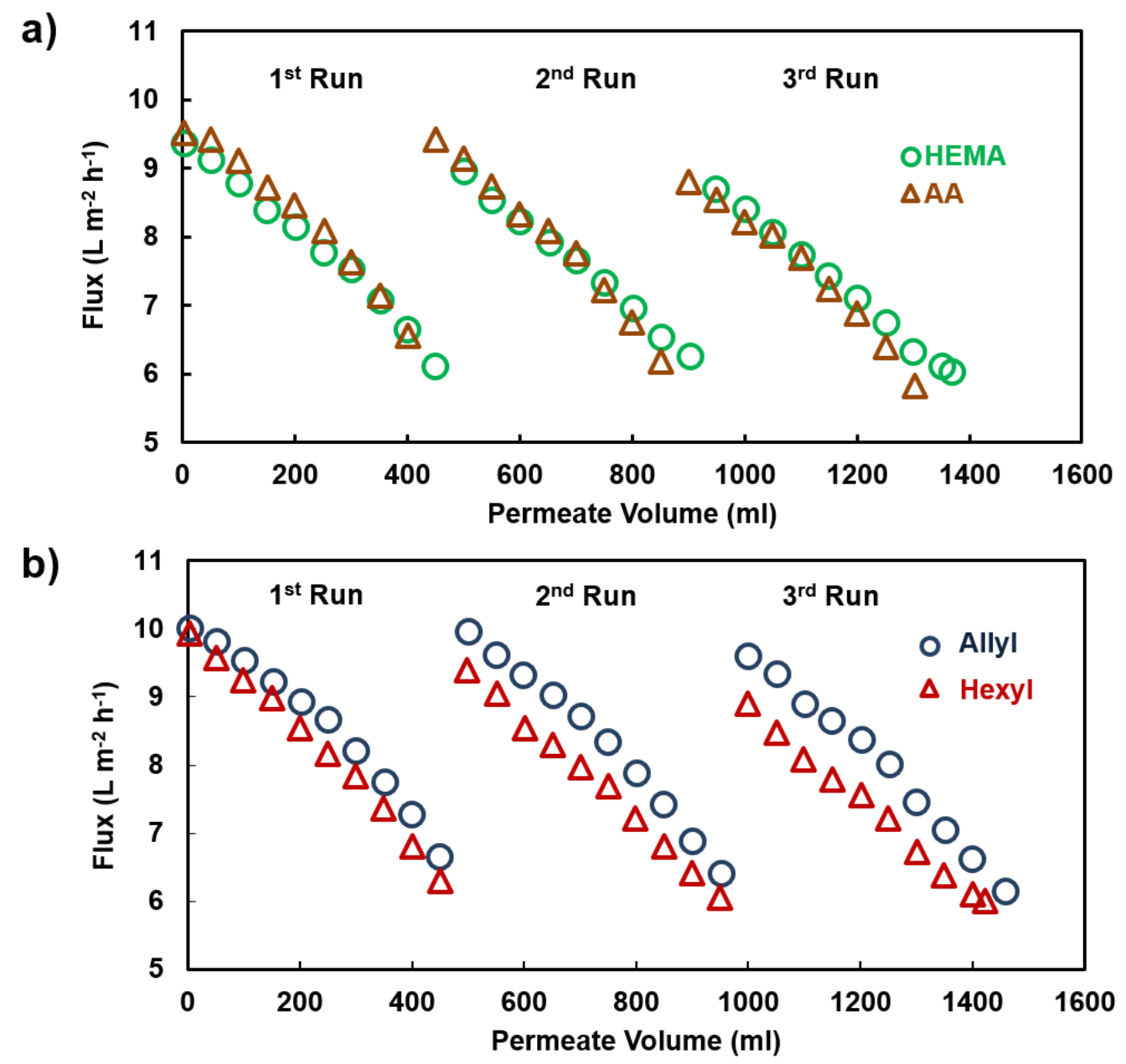

Figure 11. Water flux of modified membranes as a function of cumulative permeate volume over three MD cycles for a) HEMA and AA modified membranes b) ionic liquids modified membranes. The feed consisted of PW. MD was stopped and regeneration commenced when the flux dropped below $6.0 \mathrm{~L} \mathrm{~m}^{-2} \mathrm{~h}^{-1}$.

\subsection{Allyl modified membrane}

Since the best performance was obtained for the Allyl modified membrane, this membrane was studied in more detail. Fig. 12 gives SEM images and elemental analysis results from EDX spectroscopy after 3 MD cycles (same membrane used in Figure 11). SEM images before and after three MD cycles indicate qualitatively that rejected species that adsorb onto the membrane surface during MD, are not completely removed during regeneration. Elemental analysis of the membrane surface indicates the presence of $\mathrm{Na}, \mathrm{Mg}$, and $\mathrm{Cl}$. Table 4 indicates that these ions are 
found in the PW. Further, the appearance of a small peak for oxygen indicates adsorption of dissolved organic compounds. However, comparing the results in Figure 12 with analogous results for the base membrane (Figure 9.a and 9.d), it can be seen that the Allyl modified membrane displayed significantly less ad sorption of dissolved organic species. It is important to note that the results in Figure 9 are for three MD cycles while the result in Figure 9 is for a single MD cycle though in the case of Figure 9 the membrane was tested till pore wetting occurred. Figure 9.d suggests that the amount of deposition of inorganic salts is greater than in Figure 12.b, and in particular deposition of $\mathrm{Ca}$ is observed. However, this may be due to the fact that the membrane was tested till pore wetting occurred.

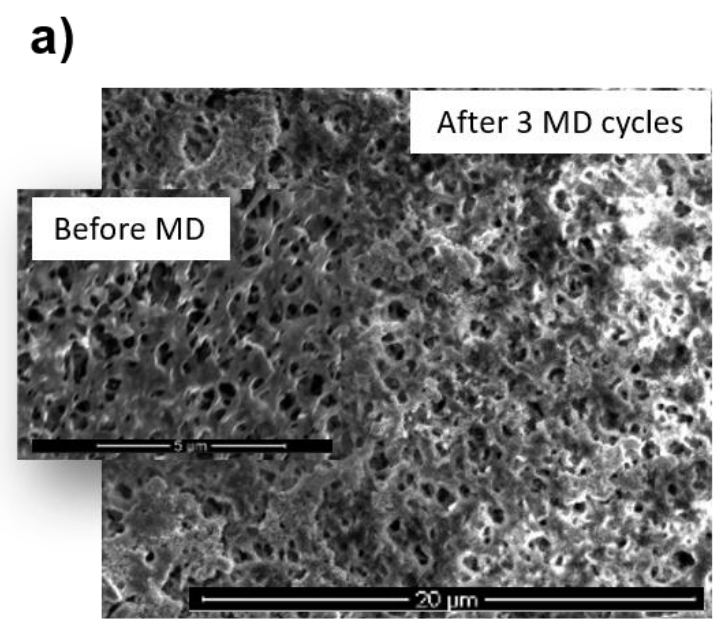

\section{b)}

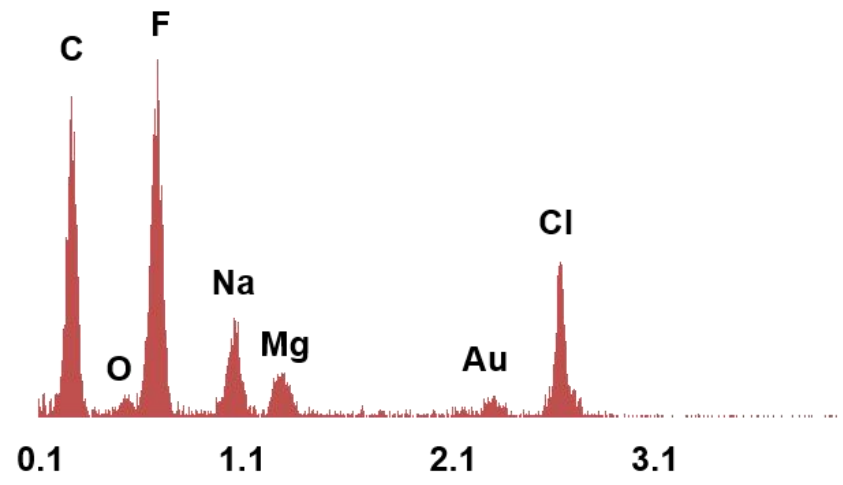

Figure 12. a) SEM image and b) EDX spectroscopy results of Allyl modified membrane after three MD cycles with PW, respectively

Finally, the Allyl modified membrane was challenged with PW pretreated by electrocoagulation and synthetic PW. The results are given in Fig. 13. Figure 13.a gives the variation of flux with permeate volume. The figure indicates that the initial flux is greatest for 
synthetic PW and lowest for PW. This is consistent with the result of the base membrane. However, for the pretreated PW and synthetic PW the initial flux is approximately constant and then declines rapidly after $200 \mathrm{~mL}$ of permeate have been collected. For the PW feed stream, a more constant permeate flux is observed. In fact, after $400 \mathrm{~mL}$ permeate have been collected, the productivity of the membrane challenged with PW is higher than the membrane challenged with pretreated PW and synthetic PW.

EDX spectroscopy based elemental analysis results are given in Figures 13.b and 13.c for pretreated PW and synthetic PW, respectively. Results for PW are given in Figure 12.b. Comparing these results with those for the base membrane, Figure 9 (d-f) it can be seen that they show similar trends with the exception for the allyl modified membrane treated with PW where minimal organic fouling is observed. The Al peak observed for pretreated PW is due to the electrocoagulation step. Thus, even after three runs, the Allyl modified membrane displays limited fouling by dissolved organic species. 


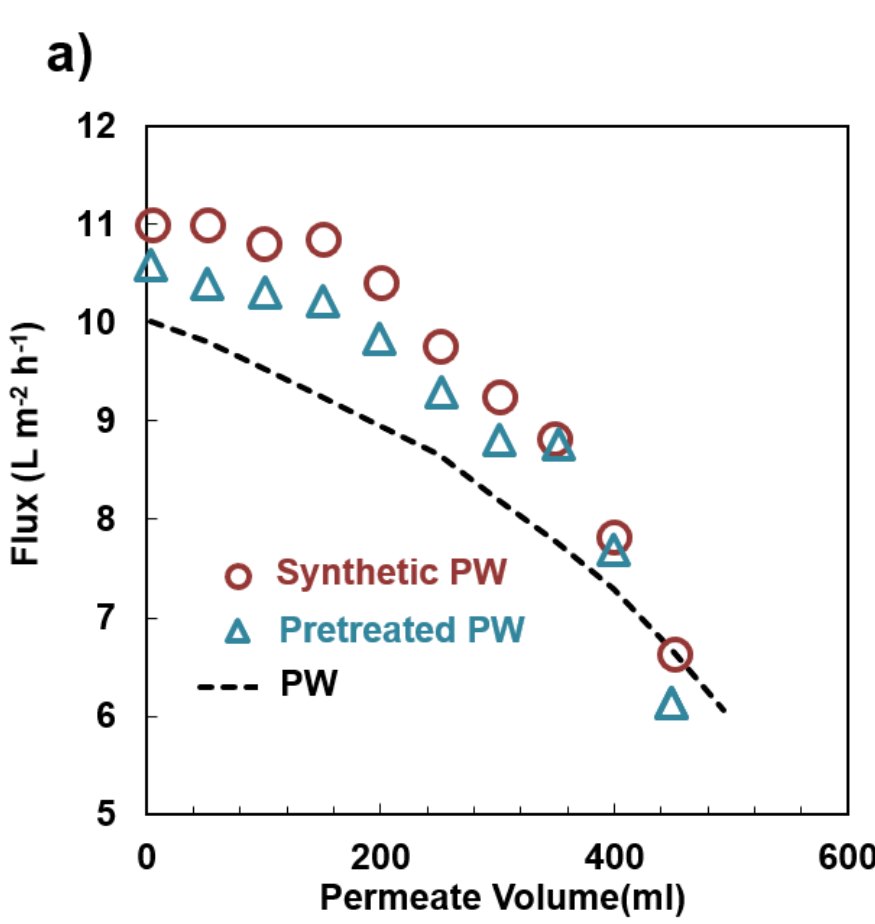

b)
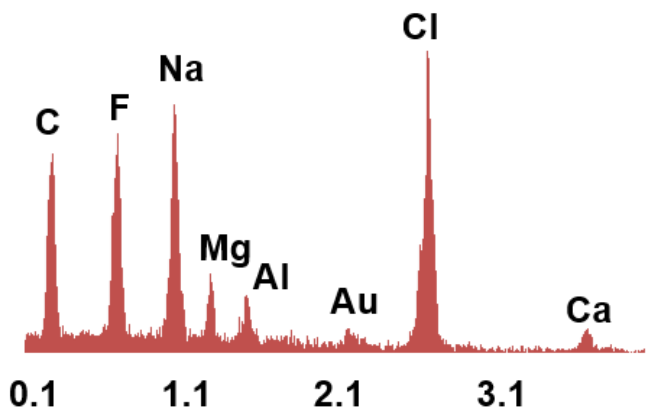

c)

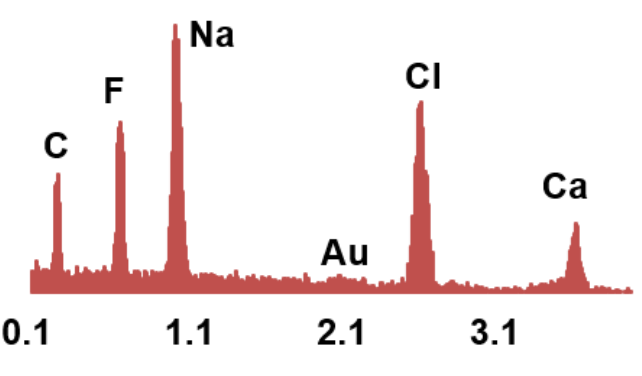

Figure 13. a) Normalized water flux of Allyl modified PVDF membrane challenges with PW, pretreated PW and synthetic PW. EDX results for Allyl modified after MD with b) pretreated PW, c) synthetic PW.

When developing a practical direct contact membrane distillation-based treatment process for PW, pretreatment of the PW will be essential. The more fouling resistant the membrane, the lower the pretreatment requirements, and the greater the membrane stability. Maximizing membrane lifetime as well as water recovery prior to membrane regeneration will be important considerations when developing a practical direct contact membrane distillation process to treat PW.

The result in Figure 13.a suggests that for the Allyl modified membrane, though the initial flux is higher for pretreated PW and synthetic PW, the volume of permeate recovered before the flux dropped below $6 \mathrm{~L} \mathrm{~m}^{-2} \mathrm{~h}^{-1}$, is greater for the PW feed stream. Yun et al. [48] show the importance of concentration polarization in MD, especially at elevated TDS. Further, the rate of scale formation will depend on the operating conditions, especially feed flow rate and permeate 
flux. The results in Figure 13.a suggests that for feed streams with low or no dissolved organic compounds, more rapid scale formation may occur at higher permeate fluxes which will compromise the volume of permeate that can be recovered prior to membrane regeneration. In the case of near saturation feed brine, the rapid increase in salt concentration adjacent to the membrane surface enables nucleation and crystal growth. The solute molecules can either physically trap in the irregular membrane surface or establish polar/electrostatic interaction with the functional groups on the surface [49]. In addition, polymer brushes can provide higher surface area for seeding of nucleation sites. While in the case of $\mathrm{PW}$, the higher concentration of organic compounds enables more hydrophobic interactions between organics and membrane surface, decreasing the flux and interfering the attraction between salt molecules and the functional groups.

The results obtained here suggest that grafting a thin nanostructure that consists of hydrophilic polymers will suppress organic fouling of the membrane can increase the volume of permeate that can be recovered prior to membrane regeneration and increase membrane stability. In addition, the results for the four different hydrophilic polymers investigated here indicate that careful tailoring of the groups present, and the structure of the monomer units is important. The two polyionic liquid based polymer chains gave the best membrane performance. In a recent w ork, Sun and Qian [50] have shown that these polyionic liquid chains are strongly hydrated by water molecules through hydrogen bonding. Thus, there is significant enthalpy and kinetic barriers to overcome for dissolved species in solution to ad sorb onto the polymer chains, which could explain the improved resistance to adsorption. These polymer chains contained repeating charged units (imidazolium ion) as well as hydrophobic segments in the repeating unit. The fact the Allyl modified membrane performs better than the hexyl modified membrane indicates the importance of tailoring the structure of the repeating monomer segments in the polymer chain. 
As indicated by Deshmukh et al. [27] suppressing adsorption by polar and non-polar organic compounds, low surface tension compounds as well as scale formation by dissolved inorganic species will be extremely challenging simply by surface modification. Optimization of the three-dimensional structure of the grafted nanostructure could provide an additional kinetic barrier to suppress adsorption onto the membrane surface. Thus, it is likely that the flexibility, grafting density, and length of the grafted polymer chains could be tailored to minimize ad sorption on the membrane.

The degree and rate of fouling also depend on the quality of the PW. We observed little deposition of calcium on the membrane surface. However, often the formation of calcium-based scales is a concern. Thus, it is likely that the pretreatment of the PW will always be necessary. The complexity of the desired membrane surface nanostructure that is grafted from the membrane surface will be a tradeoff between the additional cost of manufacturing the membrane, the reduced pretreatment costs, and the enhanced membrane stability and performance.

\subsection{Conclusion}

Membrane stability is often a concern when developing MD for treatment of PW. The hydraulic fracturing PW investigated here is challenging to treat given the presence of dissolved organic compounds as well as the high concentrations of inorganic salts. While the PVDF membrane must be hydrophobic, adsorption of organic species on the hydrophobic membrane surface can compromise membrane performance. Here, HEMA, AA, Allyl, and Hexyl polymers have been grafted from the membrane surface using UV initiated radical polymerization. By controlling the polymerization conditions, only a slight reduction in the water contact angle was observed. Base and modified membranes were challenged with PW feed streams. When the membranes were analyzed after MD, deposition of inorganic salts was observed though the 
modified membranes showed much less adsorption of dissolved organic species. In addition, the modified membranes were regenerated and reused, indicating improved membrane stability. The base membrane, and Allyl modified membranes which gave the best performance were challenged with PW that was pretreated by electrocoagulation to remove dissolved organic compounds as well as a synthetic PW that did not contain any dissolved organic compounds. Our results suggest that the Allyl modified membrane displayed similar water recovery for all three feed streams. Thus, by careful modifying the membrane surface membrane productivity and stability can be increased. It will be essential to optimize the three-dimensional structure of the grafted polymer chains as well as the chemical structure of the monomer units in order to minimize adsorption of polar and non-polar organic compounds, low surface tension compounds as well as inorganic salts. As pretreatment of the feed will always be required, the reduced pretreatment costs must be compared to the additional membrane manufacturing costs involved in grafting complex nanostructures from the membrane surface.

\subsection{Future Work}

Future work could be focused on improving membrane resistance to both scaling and organic fouling as the relationship between MD membrane fouling and scaling has yet to be established for membrane distillation. This research indicated the necessity of optimization of membrane properties for achieving an appropriate kinetic barrier to the transport of low surface tension substances and TDS in water. Modified membranes can be characterized in terms of surface free energy to optimize the synergic effect of fouling, scaling and wetting in practical systems. Grafting other types of ionic liquids that include anionic moieties or both cationic and anionic moieties such as zwitterions can be evaluated and compared to the performance of classic monomers. A systematic performance evaluation of modified membranes with various feed 
compositions including rich-surfactants feedwaters is required to ensure robustness of the membranes as amphiphilic substances may transport across the hydrophilic layer and subsequently wet the underlying hydrophobic substrate. In addition, coupled energy and cost analyses can be developed to identify the economic benefits of anti-fouling membranes for MD systems. Finally, development of scalable methods for fabrication and modification of anti-fouling membranes is essential in order to implement in an industrial scale. 


\section{References}

[1] E. T. Igunnu and G. Z. Chen, "Produced water treatment technologies," Int. J. LowCarbon Technol., vol. 9, no. 3, pp. 157-177, 2014.

[2] K. B. Gregory, R. D. Vidic, and D. A. Dzombak, "Water Management Challenges Associated with the Production of Shale Gas by Hydraulic Fracturing," Elements, vol. 7, no. 3, pp. 181-186, Jun. 2011.

[3] J. M. Neff, Produced Water. 2007.

[4] A. Fakhru'l-Razi, A. Pendashteh, L. C. Abdullah, D. R. A. Biak, S. S. Madaeni, and Z. Z. Abidin, "Review of technologies for oil and gas produced water treatment.," J. Hazard. Mater., vol. 170, no. 2-3, pp. 530-51, 2009.

[5] V. A. Kuuskraa, S. H. Stevens, and K. D. Moodhe, "Technically Recoverable Shale Oil and Shale Gas Resources: An Assessment of 137 Shale Formations in 41 Countries Outside the United States," U.S. Energy Inf. Adm., vol. 2013, no. June, p. 76 pp., 2013.

[6] N. Dakota and Q. Facts, "North Dakota State Energy Profile,” p. EIA, 2016.

[7] D. B. Burnett, "Potential for beneficial use of oil and gas produced water," Glob. Pet. Institute, Texas Water Resour. Inst., pp. 1-11, 2004.

[8] M. Padaki et al., "Membrane technology enhancement in oil-water separation. A review," Desalination, vol. 357, pp. 197-207, 2015.

[9] M. W. Shahzad, M. Burhan, and K. C. Ng, "Pushing desalination recovery to the maximum limit: Membrane and thermal processes integration," Desalination, vol. 416, no. March, pp. 54-64, 2017.

[10] C. Bellona and J. E. Drewes, "Reuse of produced water using nanofiltration and ultra-low pressure reverse osmosis to meet future water demands," p. 80, 2002.

[11] J. M. Dickhout, J. Moreno, P. M. Biesheuvel, L. Boels, R. G. H. Lammertink, and W. M. de Vos, "Produced water treatment by membranes: A review from a colloidal perspective,” J. Colloid Interface Sci., vol. 487, pp. 523-534, 2017.

[12] A. Alkhudhiri, N. Darwish, and N. Hilal, "Membrane distillation: A comprehensive review," Desalination, vol. 287. pp. 2-18, 2012.

[13] E. Curcio and E. Drioli, "Membrane distillation and related operations - A review," Sep. Purif. Rev., vol. 34, no. 1, pp. 35-86, 2005. 
[14] O. R. Lokare, S. Tavakkoli, S. Wadekar, V. Khanna, and R. D. Vidic, "Fouling in direct contact membrane distillation of produced water from unconventional gas extraction," $J$. Memb. Sci., vol. 524, no. October 2016, pp. 493-501, 2017.

[15] M. Malmali, P. Fyfe, D. Lincicome, K. Sardari, and S. R. Wickramasinghe, "Selecting membranes for treating hydraulic fracturing produced waters by membrane distillation," Sep. Sci. Technol., vol. 52, no. 2, pp. 266-275, 2017.

[16] A. L. McGaughey, R. D. Gustafson, and A. E. Childress, "Effect of long-term operation on membrane surface characteristics and performance in membrane distillation," J. Memb. Sci., vol. 543, no. May, pp. 143-150, 2017.

[17] A. Alkhudhiri, N. Darwish, and N. Hilal, "Produced water treatment: Application of Air Gap Membrane Distillation,” Desalination, vol. 309, pp. 46-51, 2013.

[18] F. Macedonio, A. Ali, T. Poerio, E. El-Sayed, E. Drioli, and M. Abdel-Jawad, "Direct contact membrane distillation for treatment of oilfield produced water," Sep. Purif. Technol., vol. 126, pp. 69-81, 2014.

[19] Z. Anari, A. Sengupta, and S. R. Wickramasinghe, "Surface oxidation of ethylenechlorotrifluoroethylene (ECTFE) membrane for the treatment of real produced water by membrane distillation," Int. J. Environ. Res. Public Health, vol. 15, no. 8, pp. 114, 2018.

[20] S. Alzahrani and A. W. Mohammad, "Challenges and trends in membrane technology implementation for produced water treatment: A review," J. Water Process Eng., vol. 4, no. C, pp. 107-133, 2014.

[21] H. Cho, Y. Choi, and S. Lee, "Effect of pretreatment and operating conditions on the performance of membrane distillation for the treatment of shale gas wastewater," Desalination, 2018.

[22] K. Sardari, P. Fyfe, D. Lincicome, and S. Ranil Wickramasinghe, "Combined electrocoagulation and membrane distillation for treating high salinity produced waters," J. Memb. Sci., 2018.

[23] W. Ho and K. Sirkar, Membrane Handbook. 2013.

[24] P. Holt, G. Barton, and C. Mitchell, "The Third Annual Australian Environmental Engineering Research Event,” vol. 1956, pp. 23-26, 1999.

[25] M. Eyvaz, E. Gürbulak, S. Kara and E. Yüksel, "Preventing of Cathode Passivation / Deposition in Electrochemical Treatment Methods - A Case Study on Winery Wastewater with Electrocoagulation" Heavy Met. Remov. with Phytoremediation, p. 13, 2014. 
[26] D. T. Moussa, M. H. El-Naas, M. Nasser, and M. J. Al-Marri, “A comprehensive review of electrocoagulation for water treatment: Potentials and challenges," J. Environ. Manage., 2017.

[27] A. Deshmukh et al., "Membrane distillation at the water-energy nexus: Limits, opportunities, and challenges," Energy and Environmental Science. 2018.

[28] A. B. D. Cassie and S. Baxter, "Wettability of porous surfaces," Trans. Faraday Soc., 1944.

[29] R. N. Wenzel, "Resistance of solid surfaces to wetting by water," Ind. Eng. Chem., 1936.

[30] Y. X. Huang, Z. Wang, J. Jin, and S. Lin, "Novel Janus Membrane for Membrane Distillation with Simultaneous Fouling and Wetting Resistance," Environ. Sci. Technol., 2017.

[31] Z. Wang, D. Hou, and S. Lin, "Composite Membrane with Underwater-Oleophobic Surface for Anti-Oil-Fouling Membrane Distillation,” Environ. Sci. Technol., vol. 50, no. 7, pp. 3866-3874, 2016.

[32] Z. Wang, J. Jin, D. Hou, and S. Lin, "Tailoring surface charge and wetting property for robust oil-fouling mitigation in membrane distillation," J. Memb. Sci., 2016.

[33] G. Zuo and R. Wang, "Novel membrane surface modification to enhance anti-oil fouling property for membrane distillation application," J. Memb. Sci., vol. 447, pp. 26-35, 2013.

[34] Y. Sui, X. Gao, Z. Wang, and C. Gao, "Antifouling and antibacterial improvement of surface-functionalized poly(vinylidene fluoride) membrane prepared via dihyd roxyphenylalanine-initiated atom transfer radical graft polymerizations," J. Memb. Sci., 2012.

[35] J. Q. Meng, C. L. Chen, L. P. Huang, Q. Y. Du, and Y. F. Zhang, "Surface modification of PVDF membrane via AGET ATRP directly from the membrane surface," Appl. Surf. Sci., vol. 257, no. 14, pp. 6282-6290, 2011.

[36] T. Swift, L. Swanson, M. Geoghegan, and S. Rimmer, "The pH-responsive behaviour of poly(acrylic acid) in aqueous solution is dependent on molar mass," Soft Matter, vol. 12, no. 9, pp. 2542-2549, 2016.

[37] E. Metcalf and H. Eddy, Wastewater engineering: treatment and reuse. 2003.

[38] M. Jebur, A. Sengupta, Y. H. Chiao, M. Kamaz, X. Qian, and R. Wickramasinghe, "Pi electron cloud mediated separation of aromatics using supported ionic liquid (SIL) membrane having antibacterial activity," J. Memb. Sci., vol. 556, pp. 1-11, 2018. 
[39] Y. Ma, L. Liu, and W. Yang, "Photo-induced living/controlled surface radical grafting polymerization and its application in fabricating 3-D micro-architectures on the surface of flat/particulate organic substrates," Polymer (Guildf)., vol. 52, no. 19, pp. 4159-4173, 2011.

[40] Z. Feng and B. Rånby, "Photoinitiated surface grafting of synthetic fibers, I. Photoinitiated surface grafting of ultra high strength polyethylene fibers," Die Angew. Makromol. Chemie, vol. 195, no. 1, pp. 17-33, 1992.

[41] R. J. Vonk et al., "Post-polymerization photografting on methacrylate-based monoliths for separation of intact proteins and protein digests with comprehensive two-dimensional liquid chromatography hyphenated with high-resolution mass spectrometry," Anal. Bioanal. Chem., vol. 407, no. 13, pp. 3817-3829, 2015.

[42] D. Ghernaout, B. Ghernaout, A. Saiba, A. Boucherit, and A. Kellil, "Removal of humic acids by continuous electromagnetic treatment followed by electrocoagulation in batch using aluminium electrodes," Desalination, vol. 238, no. 1-3, pp. 295-308, 2009.

[43] J. N. Hakizimana et al., "Electrocoagulation process in water treatment: A review of electrocoagulation modeling approaches," Desalination, vol. 404, pp. 1-21, 2017.

[44] C. A. Martínez-Huitle and E. Brillas, "Decontamination of wastewaters containing synthetic organic dyes by electrochemical methods: A general review," Appl. Catal. B Environ., vol. 87, no. 3-4, pp. 105-145, 2009.

[45] F. Yalcinkaya, A. Siekierka, and M. Bryjak, "Surface modification of electrospun nanofibrous membranes for oily wastewater separation," $R S C A d v$., vol. 7, no. 89, pp. 56704-56712, 2017.

[46] K. Nakanishi and P. H. Solomon, Infrared Absorption Spectroscopy, vol. 26, no. 1952. 1977.

[47] H. Li, X. Wang, L. Cao, X. Zhang, and C. Yang, "Gold-recovery PVDF membrane functionalized with thiosemicarbazide," Chem. Eng. J., vol. 280, pp. 399-408, 2015.

[48] Y. Yun, R. Ma, W. Zhang, A. G. Fane, and J. Li, "Direct contact membrane distillation mechanism for high concentration $\mathrm{NaCl}$ solutions," Desalination, vol. 188, no. 1-3, pp. 251-262, 2006.

[49] M. T. Chan, A. G. Fane, J. T. Matheickal, and R. Sheikholeslami, "Membrane distillation crystallization of concentrated salts - Flux and crystal formation," J. Memb. Sci., vol. 257, no. 1-2, pp. 144-155, 2005.

[50] X. Sun and X. Qian, "Elucidating the Energetics and Effects of Solvents on Cellulose Hydrolysis Using a Polymeric Acid Catalyst," Appl. Sci., vol. 8, no. 10, p. 1767, 2018. 